
\title{
$\begin{array}{ll}\text { Research Square } & \begin{array}{l}\text { Preprints are preliminary reports that have not undergone peer review. } \\ \text { They should not be considered conclusive, used to inform clinical practice, } \\ \text { or referenced by the media as validated information. }\end{array}\end{array}$
}

\section{The Evidence Mapping and Methodological Quality of Clinical Practice Guidelines of Diagnosis and Management for Spinal Pain: A Cross-Sectional Survey}

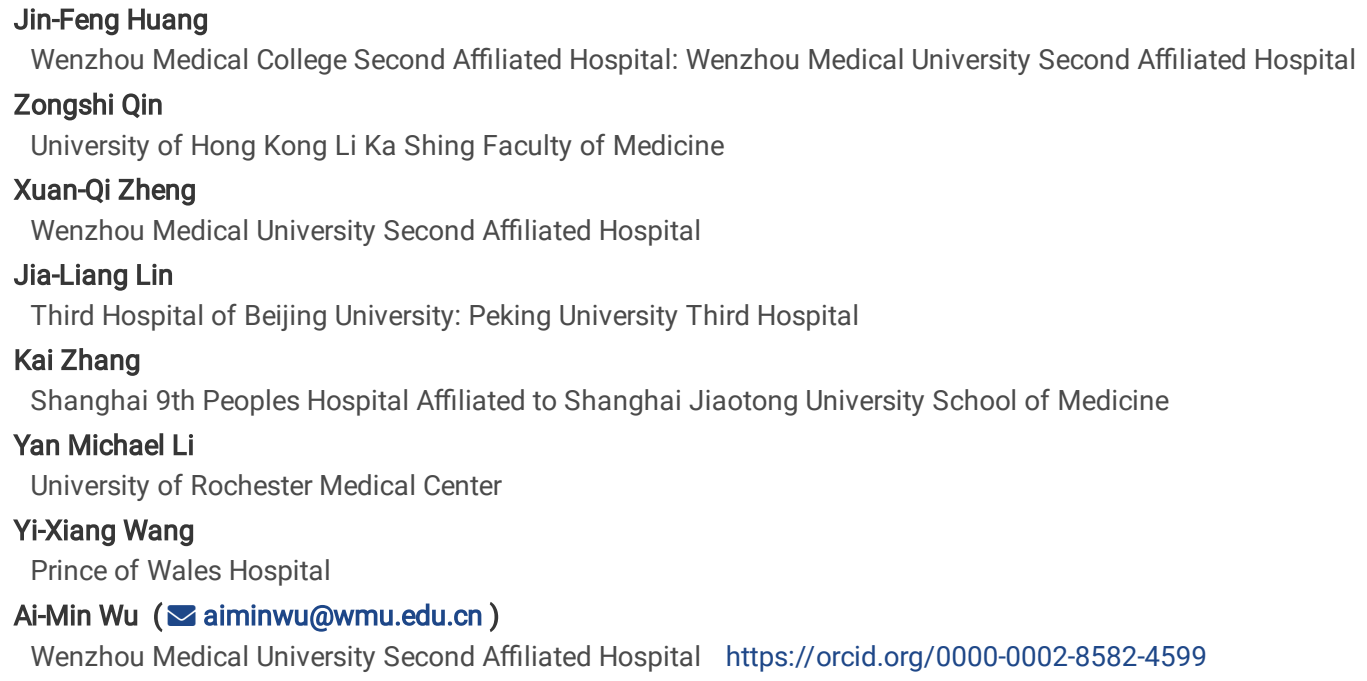




\section{Abstract}

Objectives: To systematically review clinical practice guidelines (CPGs) for treating spinal pain, to assess the quality of different CPGs, and finally to provide an evidence map for the specific explication of research trends and gaps.

Method: We searched CPGs in PubMed, Embase, Web of Science, Guidelines International Network (GIN), National Health and Medical Research Council (NHMRC), Scottish Intercollegiate Guidelines Network (SIGN) and the National Institute for Health and Care Excellence (NICE). We extracted basic information, recommendations, methodological quality, and reporting quality of the CPGs. Four researchers independently evaluated the quality of the CPGs according to the Appraisal of Guidelines Research and Evaluation (AGREE II) and Reporting Items for Practice Guidelines in Healthcare (RIGHT).

Results: We included 21 CPGs into our study. According to the AGREE II checklist, we found that the mean score was relatively high in four domains, namely, scope and purpose (78.39), stakeholder involvement (63.04), clarity of presentation (72.04), and rigor of development (61.25). However, the mean score of two domains (editorial independence and application) was relatively low. Among the seven domains of the RIGHT checklist, one field (basic information) had the highest reporting rate (86.61\%), while another field (funding, declaration, and management of interest) obtained the lowest reporting rate (53.00\%).

Conclusion: Our study provided evidence mapping, which is a good tool to reduce research waste and facilitate the process of knowledge transfer. We found the mean score of the application of included CPGs was the lowest and most of CPGs didn't consider patient preferences. Therefore, guideline makers should concentrate on patient preference and application in future guidelines. The results of our study can also be used to optimize the implementation of these recommendations and to improve the development of reliable CPGs for treating spinal pain.

\section{What Is New?}

1. The recommendations of different guidelines were summarized in evidence mapping, which is a good tool to reduce research waste and facilitate the process of knowledge transfer.

2. Currently, clinical practice guidelines (CPGs) of low methodological quality are still being developed and published. Identifying the quality and limitations of recent CPGs could be useful for future development of CPGs. No studies have systematically examined the methodological quality of recent spinal pain CPGs. Our study offered a comprehensive assessment of methodological quality of recent spinal pain CPGs.

3. We found the mean score of the application of included CPGs was the lowest and most of CPGs didn't consider patient preferences. The results of methodological quality could help guideline developers identify the limitations of recent guidelines and then promote improvement in the development of reliable CPGs for treating spinal pain

\section{Introduction}

Spinal pain includes cervical spine pain, low back pain and sciatica.[1-3] It is one of the leading causes of disability and loss of human labor capacity worldwide.[4-10] Approximately 50-85\% of the population has back pain for some period over their lifetimes.[11]'[12] The incidence of neck pain was reported to be approximately $20-40 \%$ in adolescents and to increase as age increases.[13, 14] Approximately $2-14 \%$ of the population suffers from sciatica. $[15,16]$ The annual cost of treating spinal pain ranks third behind diabetes and heart disease treatment.[17] Therefore, spinal pain is a serious public health problem that creates many problems in people's daily lives.

Clinical practice guidelines (CPGs) for treating spinal pain can help improve the quality of care. Care following CPG recommendations can result in better outcomes and lower costs.[18, 19] However, various organizations give conflicting CPGs and recommendations.[20] Furthermore, CPGs have potential issues; for example, several CPGs include voluminous documents that are not user-friendly,[21] and there are shortcomings in their quality[22, 23], which may limit clinical use.[24] Some contemporary spinal pain CPGs are of poor quality and have the same problems as mentioned above.[24] Therefore, we conducted a systematic evaluation and investigation of the quality of different spinal pain CPGs.

Evidence mapping, an emerging rapid and accurate review method, includes systematic search and specific characterization of existing studies on topics of interest.[25] Evidence mapping aims to identify the gap between different studies to open avenues for future research.[25] In our study, the evidence mapping method was used to visually present different CPGs regarding diagnosis, management strategies and conflict recommendations of spinal pain care.

The Appraisal of Guidelines Research and Evaluation (AGREE II) and Reporting Items for Practice Guidelines in Healthcare (RIGHT) are commonly used checklists to assess the quality of CPG. The international RIGHT Working Group followed an existing framework for developing guidelines and the EQUATOR (Enhancing the Quality and Transparency of Health Research) Network approach to build the RIGHT checklist.[26] The RIGHT checklist can not only help developers in reporting guidelines but also help health care practitioners understand and implement guidelines.[26] AGREE II was developed to address the issue of variability in guideline quality. It is a tool that assesses the methodological rigour and transparency in which a guideline is developed.

In present study, the aim is to systematically review CPGs for treating spinal pain, to assess the quality of different CPGs, and finally to provide an evidence map for the specific explication of research trends and gaps.

\section{Methods}

\section{Search strategy and selection criteria}


We defined CPGs as being identified by authors and being consistent with the definition of the Institute of Medicine.[27] We searched for CPGs in PubMed, Embase and Web of Science using medical subject headings (MeSH) and keywords. We also searched some online guideline websites: Guidelines International Network (GIN), National Health and Medical Research Council (NHMRC), Scottish Intercollegiate Guidelines Network (SIGN) and the National Institute for Health and Care Excellence (NICE).

The database search combined MeSH and key words related to CPGs and the spinal pain conditions of interest (Supplementary File 1). A previous study indicated that CPGs developed or updated within the previous 5 years can better reflect latest research evidence.[27] The search range was January 2013 to December 2018. In June 2020, the results were updated according to the same search strategy.

Inclusion criteria: 1. Published between January 2013 and June 2020; 2. Guidelines on spinal pain; 3 . The guideline aims at diagnostic evaluation and disease management; 4. For general populations (aged >18 years); 5 . Restriction to English only; and 6. For guidelines with multiple versions, only the latest version was included.

Exclusion criteria: 1. CPGs only focused on complementary and alternative medicine (acupuncture, herb medicine, etc.). 2. CPGs for spinal pain caused by trauma or a specific disease process (ankylosing spondylitis, rheumatoid arthritis, infection, cancer, etc.). 3. CPGs that address care recommendations for specific systems/organizations.

\section{Study process}

Teams of paired reviewers, trained in trial and systematic review methods, screened abstracts and full texts for eligibility and abstracted data from eligible studies independently and in duplicate, using pilot-tested, standardized forms, together with detailed instructions. The reviewers resolved disagreements through discussion or, if needed, adjudication by a third reviewer.

\section{Data extraction}

We collected the following information from each eligible CPG: (1) title, (2) authors, (3) locations country, (4) year of publication, (5) publication organization, (5) type of organization, (6) funding information, (7) methods of forming guideline, (8) grading system and (9) recommendations.

\section{Classifying recommendations}

Two authors independently reviewed and classified the recommendations. We classified recommendations into four groups, namely, 'recommended to do', 'could be considered to do', 'do not recommend to do' or 'uncertain/unclear', to accommodate the various terminologies used in CPGs. For a particular topic, if there were no recommendations provided by the CPG, or if it was out of scope of the CPG and was not included, it was not classified.

\section{Narrative summary}

Two authors initially developed a narrative summary including classifying recommendations into different theme areas, and these were then reviewed and refined by all other authors. Our author group included academic and practicing physiotherapists, MSK pain researchers, an indicator development researcher, an emergency care physician, a senior medical officer in emergency medicine and a pain medicine physician.

\section{Assessment of guideline quality}

AGREE II and RIGHT were used to assess the quality of CPGs. The RIGHT checklist can help report guidelines. AGREE II was developed to assess the variability in guideline quality. Four independent reviewers were trained to perform CPG appraisals, and they independently reviewed and scored each eligible CPG.

The AGREE II instrument includes six main domains: scope and purpose; stake holder involvement; rigor of development; clarity of presentation; applicability; and editorial independence. $[28,29]$ Then, we calculated overall AGREE II scores for each CPG. We defined "strongly recommended" as overall scores $>60 \%$, "recommended with modifications" as overall scores between $30 \%$ and $60 \%$, and "not recommended" for scores $<30 \%$.[30]

Then, we used RIGHT to assess the quality of each CPGs. The RIGHT checklist includes 22 items with a total 35 scores: basic information (items 1-4), background (items 5-9), evidence (items 10-12), recommendations (items 13-15), review and quality assurance (items 16-17), funding, declaration and management of interests (items 18-19), and information (items 20-22).[26] Four reviewers independently assessed the quality of each CPGs by using "Yes", "No", and "Partial" for each item according to the RIGHT checklist.

Finally, we combine AGREE II and RIGHT to define the quality of CPGs. We defined the quality of CPGs with both AGREE II scores $>60 \%$ and RIGHT scores $>20$ as high quality. We defined the quality of CPGs with AGREE II scores between $30 \%$ and $60 \%$ or RIGHT scores between 10 and 20 as middle quality. We defined the quality of CPGs with AGREE II scores $<30 \%$ or RIGHT scores $<10$ as low quality.

\section{Data synthesis and analysis}

\section{Statistical analysis}

For each CPG, we calculated the AGREE II score for each domain and overall scores as a percentage of the maximum possible score and standardized range. Then, we calculated the mean and standard deviation (SD) for six main domains.

The number of RIGHT checklist items reported in each CPG was presented to assess the reporting quality data. 


\section{Summarizing and grading the quality of CPGs}

After completing the AGREE II score and RIGHT score, we summarized two scores simultaneously to visualize the quality of each CPG. The darkness of the bubbles represented the quality of CPGs (green: high; yellow: middle; red: low).

\section{Patient and public involvement}

Patients and/or the public were not involved in this research.

\section{Results}

Twenty-one CPGs [31-51] met the inclusion and exclusion criteria, of which seven (33.3\%) were devoted to neck pain[31, 33-37, 52] (i.e., Canada, KNGF, APTA, DHA, OPTIMa, Scottish and SIMFER CPGs), fourteen (66.6\%) CPGs were devoted to back pain[36, 38-50] (i.e., ACP, ACl, Belgium, Canada, DHA, German, Globe et al., NDMG, KNGF, Scottish, Colorado, TOP, VA/DoD and NICE CPGs), and 3 (14.3\%) CPGs were devoted to sciatica[41, 50, 51] (i.e., DHA, NASS and NICE CPGs). Some guidelines contained more than one site. The study flow diagram is shown in Figure 1.

\section{Characteristics of included CPGs}

Table 1 shows the characteristics of the included CPGs. The included CPGs were from 11 individual countries, most of which are developed countries. Most were from the USA $(n=6)$ and Canada $(n=4)$. The Netherlands, Denmark and Germany each contributed two CPGs. The American CPGs mostly focused on LBP $(n=4)$, and half of the CPGs from Canada were for neck pain $(n=2)$. Most CPGs were developed by medical specialty societies $(n=13,61.9 \%)$, followed by governmental bodies $(n=6,26.1 \%)$ and guideline developer organizations $(n=3,13.0 \%)$.

\section{Quality}

The highest mean score was $78.39 \pm 13.34$ for scope and purpose, and the lowest mean score was $40.67 \pm 22.61$ for applicability. Generally, nine CPGs had overall scores higher than $60 \%$; these CPGs were deemed as strongly recommended for clinical care[34-36, 38, 39, 41, 42, 49, 50], ten CPGs were defined as recommended with modifications[31-33, 40, 44-48, 51] , and three CPGs were deemed as not recommended[37, 43, 47]. The mean and SD of AGREE II scores for each domain and overall scores of various guidelines are shown in Table S1 and Figure 2A. The brief overall scores of CPGs are shown in Table S2.

The RIGHT checklist contains 22 requirements organized into 7 sections, with a total of 35 items. According to the RIGHT checklist, the CPGs with the largest number of reported items was NICE, DHA and SIGN (RIGHT score $=34)$, followed by OPTIMa (RIGHT score $=31)$ and Canada Guideline $(\mathrm{RIGHT}$ score $=30)$. Among the seven domains of the RIGHT checklist, field one (basic information) had the highest reporting rate (86.16\%), and field six (funding, declaration and management of interest) obtained the lowest reporting rate (53.00\%). The numbers of reported items are shown in Table 2 . The mean compliance rates of each item are shown in Figure 2B. AGREE II and RIGHT were combined to calculate the quality of the CPGs (Figure 3).

\section{Summarizing recommendations for spinal pain}

Figure 4 summarizes the various strengths of recommendations of CPGs for neck pain and low back pain patients. Table 5 summarizes the various recommendations of assessment, diagnosis, and management of spinal pain CPGs.

\section{Neck pain}

\section{Patient-centered care}

Most CPGs suggested that clinicians should provide patient-centered care that can lead to better outcomes. Patient-centered care included care methods such as providing individualized care[31-33], providing information for patients in a reassuring manner,[34] and shared decision-making[35].

\section{Exclude serious pathology/red flag conditions and classify the stage of neck pain}

Five CPGs offered recommendations regarding screening patients for potentially serious or structural pathology or for 'red flag' conditions at the initial assessment.[32, 33, 35-37] For example, clinicians should determine if there is a fracture, malignancy, infection, inflammatory cause of pain or another pathology reason.

Two CPGs mentioned that classification of neck pain grades should be conducted at the initial assessment.[32, 35] Three CPGs stated that one should classify neck pain as acute, subacute or chronic. $[31,33,36]$ Then, management should be provided based on the stage of neck pain.

\section{Conduct physical examination and assess psychosocial factors}

Four CPGs recommended that clinicians or physical therapist conduct comprehensive physical examinations to determine patients' baseline status.[32, 33, 36, 37] The aim of the physical examination is to help diagnose and classify neck pain disorders. Three CPGs advised assessment of psychosocial factors, which are important factors for prognosis.[32, 35, 36]

\section{Evaluate patient progress}

Three CPGs recommended evaluating patient progress and using validated outcome measures.[32, 33, 35] Outcome measures included numeric pain rating scale and the patient-specific functional scale[32], utilizing easily reproducible activity limitation and participation restriction measures[33] and self-rated 
recovery questions.[35]

\section{Provide education or information}

Six CPGs strongly recommended providing education or information for patient about their condition and management methods.[31-36] Education is a part of first-line, essential treatment. Common education consisted of providing structured and individualized education[34-36] such as advice, training, supervision, instruction, prognosis, encouragement, reassurance and pain management[31-33]. However, one CPG indicated that there was insufficient evidence to prove the effect of educational interventions for patients with neck pain.[37]

\section{Patients should do physical activity or exercise}

All CPGs recommended that patients to perform physical activity or exercise.[31-37] Exercise (e.g., strengthening, endurance and flexibility exercises) was recommended for the treatment of acute and chronic neck pain for both short- and long-term benefits.[31, 32, 36, 37] One CPG showed that clinicians could use exercise therapy for management of neck pain.[35] Two CPGs mentioned that exercise should/could combined with manual therapy.[34, 37]

\section{Manual Therapy}

All CPGs recommended that patients receive manual therapy to relieve pain. Manual therapy (manipulation and/or mobilization) combined with other modalities was recommended for treating both acute and chronic neck pain.[31-37] One CPG recommended manipulation alone for patients with acute neck pain and combination therapy for chronic neck pain.[37] However, for massage, the recommendations of different CPGs differed. Two CPGs recommended massage combined with other treatments to treat chronic neck pain.[31,37] One CPG stated that clinicians could consider massage to be a potential treatment method.[32] Two CPGs did not recommend massage to treat neck pain.[34, 35]

\section{Cervical collar}

One CPG suggested that a cervical collar could be considered only if primarily advised treatments are ineffective.[32] Another CPG stated that short-term use of cervical collar can be considered for patients with acute neck pain with radiating pain.[33] One CPG did not recommend the use of cervical collar,[35] and one CPG indicated that there was insufficient evidence to give a recommendation[37].

\section{Pharmacotherapy}

Some CPGs recommended nonsteroidal anti-inflammatory drugs (NSAIDs),[34, 36] paracetamol,[37] tramadol[34] or muscle relaxants[36] after careful consideration of adverse events, contraindications, and patient preference. Furthermore, the duration should be short. However, one CPG did not recommend the use of paracetamol and recommended that clinicians consider the use of muscle relaxants.[35] For opioids, clinicians must carefully consider before using and only use these drugs in the short to medium term when other therapies have been insufficient.[34, 36]

\section{Low back pain}

\section{Assessment}

Clinicians were recommended to systematically collect formal histories[36, 38, 39, 41, 44-50] and physical examinations[36, 39, 41, 44-47, 49, 50], identifying serious pathology (i.e., red flags)[36, 39-41, 44-50], and classifying acute, subacute and chronic pain[36, 38, 41, 48-50], initially. Some CPGs also recommended that clinicians assess psychosocial factors[36, 39-50] such as STarT Back and Örebro questionnaires[36, 39-41, 45, 48, 50].

\section{Routine use of radiological imaging}

Nine CPGs were against routine use of radiological imaging for LBP.[39-42, 44, 45, 48-50] Imaging should be considered only if the results influence the management method[40,47, 50], if there are clinical reasons to suspect serious underlying pathology (i.e., red flags) [39, 41, 42, 44, 47-49] or if symptoms worsen after a period of formal treatment according to the guideline[43, 45, 49].

\section{Provide education and exercise therapy}

Most CPGs recommended patient education[36, 39-46, 48-50] (e.g., explaining the expected course, advising to remain active and providing information about self-management options) and exercise therapy[36, 38-46, 48-50] as the first-line choice for the management of acute, subacute and chronic low back pain.

\section{Manual Therapy}

Three CPGs recommended manual therapy for acute[38], subacute[38], and chronic low back pain. One guideline indicated manual therapy could be considered for short-term pain relief for chronic LBP.[36] In addition, some guidelines suggested that manual therapy could be applied if self-care and medication therapy did not provide significant improvements[39] or that it could be offered as a part of multimodal management[40,42, 49, 50].

One CPG recommended massage for treating acute and subacute low back pain[38], while two guidelines indicated that massage was not recommended for acute low back pain but could be considered for chronic low back pain[43,44]. One guideline stated that there was insufficient evidence to show the effect of manual therapy including massage.[48]

\section{Pharmacotherapy}


For the management of chronic low back pain, nonpharmacologic therapy should be the primary treatment. For those who have had an inadequate response to nonpharmacologic therapy, pharmacologic treatment should be considered. For pharmacologic treatment, NSAIDs should be treated as a first-line therapy[38, 39, 45, 49] and should be given in the lowest effective dose and for the shortest period[45, 50]. One CPG stated that NSAIDs should only be offered in addition to usual care for acute LBP[42].

Two CPGs recommended paracetamol as the first choice and NSAIDs as the second choice of pharmacotherapy for LBP management.[39, 48] In contrast, many CPGs did not recommend paracetamol to treat LBP[40, 42, 43, 45, 49, 50].

The recommendations for muscle relaxants were conflicting. One CPG recommended muscle relaxants[38], and three CPGs stated that nonbenzodiazepine muscle relaxants can be considered[47, 48]. Three CPGs did not recommend muscle relaxants[40, 43, 47].

Antidepressants could be considered to manage chronic LBP[36, 38, 40, 43, 48, 49].

Most CPGs recommended the use of opioids only if NSAIDs were ineffective, not tolerated, or contraindicated[40, 50] or if common care failed and if the known risks and realistic benefits were discussed with patients[36, 38, 41].

\section{Epidural steroid injection}

Most CPGs had a consensus opinion about epidural steroid injection. They were all against epidural steroid injection for patients without radiculopathy[4850], long-term reduction of radicular low back pain[49], or spinal stenosis[49]. For patients with acute or subacute severe radicular pain[40,50] or for very shortterm reduction of radicular low back pain[49], an epidural steroid injection can be considered.

\section{Surgery}

For patients with the following situations, surgery can be considered: 1 . severe and disabling pain persisting after nonsurgical treatment[42, 47,48$] ; 2$. radicular symptoms, symptoms of neurogenic claudication, or severe stenosis[47, 48]; and 3. nerve root compression proved by MRI or CT[47]. In addition, NICE did not recommend disc replacement or spinal fusion for low back pain[50].

\section{Sciatica}

Two CPGs did not recommend routine use of imaging for patients with sciatica[42, 50], while one CPG recommended MRI for patients with history and physical examination findings consistent with sciatica[51]. Exercise and manual therapy can be considered to treat sciatica, but only as a part of multimodal treatment[42,50]. NICE recommended antidepressants and gabapentin as initial treatment for neuropathic pain[50]. Epidural steroid injection was recommended to relieve severe radicular pain[50,51]. For surgery, one guideline recommended discectomy, which can provide more effective pain relief than other care for patients with sciatica whose symptoms warrant surgery treatment[51]. However, another CPG suggested that clinicians consider spinal decompression for patients with sciatica when nonsurgical treatment is ineffective in improving pain or function and their radiological findings are consistent with sciatic symptoms[50].

\section{Discussion}

A total of $21 \mathrm{CPGs}$ were identified in our international review of CPGs on the management of spinal pain. According to the results of guideline quality assessment, it was obvious that the quality of different CPGs varied considerably. In a recent study, we identified nine relatively high-quality CPGs[34-36, 38, $39,41,42,49,50]$. According to a standardized grade system, the several organizations summarized their recommendations for spinal pain care. We found that the recommendations and the strength of the recommendations varied widely among the CPGs, which may lead to confusion on the part of clinicians and patients or may even lead to inappropriate management regimes. Therefore, in our study, we tried to systematically evaluate and summarize the recommendations from various CPGs to provide a simple and clear consensus of current management of spinal pain for clinicians, researchers, healthcare managers, and policymakers. Our results could also help improve the quality of clinical care for spinal pain.[53, 54]

Our findings were consistent with those of previous reviews.[55-60] Advice, education, and exercise were recommended as first-line treatments for spinal pain. For neck pain, Cohen et al. recommended that clinicians should conduct a thorough history and physical examination to distinguish neuropathic pain from mechanical neck pain and provide nonpharmacological alternative treatments before pharmacological treatments.[56] The authors also showed that there was moderate and weak evidence to support NSAIDs for acute and chronic neck pain and muscle relaxants for subacute neck pain associated with muscle spasm.[56] These results were similar to our findings.[34, 36] For sciatica, Jensen et al. indicated that most patients improved after conservative treatments such as exercise, manual therapy, and self-management and that imaging should not be routinely used.[60]

Though surgery may speed up recovery, the effect was similar to conservative care over the long term.[60] Surgery can be considered if symptoms do not improve after 6-8 weeks of conservative treatment.[60] Epidural corticosteroid injections only reduce short-term pain and disability caused by sciatica, but not back pain.[61] For acute low back pain, there was high-quality evidence to support the use of pharmacological therapies (e.g., NSAIDs, muscle relaxants and paracetamol) and exercise, moderate-quality evidence to support use of acupuncture, and low-quality evidence to support manual therapy.[4] For persistent low back pain, there was high-quality evidence to support the use of exercise and antidepressants, moderate-quality evidence to support acupuncture, TENS, psychotherapy and opioids, low-quality evidence to support NSAIDS and massage and very low-quality evidence to support paracetamol, muscle relaxants and manual therapy.[4] However, that evidence was only based on short-term pain outcomes and did not weigh against the risk of harm. Therefore, the results of that review may provide different opinions from those of the present review. 
In our study, we found that most CPGs consistently recommended against the routine use of imaging. The problem of indiscriminate imaging is serious, possibly contributing to the waste of medical resources and unnecessary exposure to radiation. In previous surveys, approximately one-quarter of patients with recent-onset low back pain undergo imaging.[62,63] The abuse of imaging was worse in emergency departments. [64-66] Therefore, both patients and clinicians should know the indications of imaging for spinal pain as we concluded above.

\section{Physical activity}

In our study, most CPGs recommended physical activity/exercise for managing spinal pain. However, we needed to know the different patterns of physical activity between work and leisure.[67] Previous studies showed that physical behavior at leisure time can reduce the risk of NP and LBP.[68-71] Furthermore, Sitthipornvorakul et al. pointed out that increased both work and leisure physical activity can reduce risk of spinal pain.[72] However, previous studies indicated that the reduced risk of spinal pain was associated with increased sitting at work in working populations.[73-76] Therefore, for the different populations, the recommendation should be varied. For the white-collar population, it was recommended to increase physical activity both in work and leisure time, while the blue-collar population, it was recommended that they should limit work intensity and increase rest time at work as well as perform physical activity during leisure time. Physical activity was highly recommended; however the ideal duration, intensity and methods of training remain unclear. [77] Therefore, future studies should focus on the ideal duration, intensity and methods of physical activity.

\section{Manual Therapy}

Cervical manipulation and mobilization produced similar immediate-term or short-term effects.[78] Previous studies showed that combinations of manual therapy and other common therapies (e.g., education and exercise) were more effective for pain relief and function rehabilitation.[79-82] Similarly, in our study, all CPGs recommended manual therapy combined with other treatments for treating both acute and chronic neck pain.[31-37] Furthermore, Palmlöf et al. pointed out thatexpectations of recovery were important prognostic factors for neck pain patients seeking manual therapy.[83] Therefore, before undergoing manual therapy, it is important to assess the expectations of the recovery of patients. A previous review showed the effectiveness ofmanual therapy.[84] More recent studies also pointed out that manual therapy does have a role in relieving pain and improving function for low back pain.[8587] Though manual therapy can be delivered as a standalone therapy, it is commonly offered as a part of a multitreatment package.[88] This finding was consistent with some relatively high-quality CPGs in our study.[40, 42, 49,50]

\section{Acupuncture}

For acupuncture, different CPGs gave varying recommendations. Most CPGs recommended against acupuncture for treating spinal pain, while only a few $\mathrm{CPGs}$ recommended acupuncture for short-term pain relief. Brian et al. suggested that acupuncture can be used to treat back pain when the following conditions are met: 1 . no response to most medical treatments; 2 . exclusion of serious pathology; and 3. specific request for a referral for acupuncture on the part of the patient.[89] Trinh et al. indicated that acupuncture was relatively safe but only provided short-term pain relief for neck pain.[90] Though acupuncture was effective in relieving pain associated with sciatica[91], DHA and NICE have different opinions[42, 50]. In general, acupuncture can be considered only for short-term pain relief, but does not have a long-term benefit for spinal pain patients.

\section{Pharmacotherapy}

Previous studies have shown the effect of NSAIDs $[92,93]$ and muscle relaxants $[92,94]$ for the alleviation of pain and disability in patients with acute, subacute, and chronic low back pain and antidepressants only for chronic low back pain $[95,96]$. Short-term opioid therapy has analgesic benefits for low back pain; however, adverse effects must be considered.[97] The effectiveness of long-term opioid therapy for back pain remains unclear.[97] Similar to what we concluded above, opioids should only be used when other treatments failed and for short periods. NSAIDs are not effective in reducing pain or disability for patients with sciatica.[98]

Systemic corticosteroids, anticonvulsants and antidepressants showed statistically significant effects in reducing sciatica pain.[99-102] There was no sufficient evidence to show the effects of paracetamol, benzodiazepines, or opioids for treating sciatica.[100, 103, 104] In addition, previous systematic reviews pointed out that three commonly used medicines (NSAIDs, paracetamol and opioids) did not provide clinically important effects for spinal pain.[2, $105,106]$ Therefore, new analgesics or new pharmacotherapy regimes for spinal pain are needed.

CPGs of low methodological quality are still being developed and published.[107, 108] Previous studies mentioned that recent guidelines failed to clearly show the selection criteria of the literature, to adequately describe the strengths and limitations of included literature and to specifically describe the methods used to formulate recommendations.[109] Wong et al. stated that future high-quality guidelines should focus on providing clear implementation strategies and the applicability to specific populations.[110] Our results also indicated that the mean score of the application was the lowest. Besides, some CPGs included in our study seem to be too complex and long to get points. Readers may end up "giving up" reading everything and may miss something "important". Therefore, guideline makers should concentrate more on how to convey the information quickly and easily and the application of the clinical guidelines.

Evidence-based decision-making was proved to have favorable health and economic outcomes.[111] However, current real-world practices differ substantially from recommendations in evidence-based guidelines. Patient preferences are becoming increasingly important in healthcare policy decision-making.[112, 113] However, most included guidelines did not consider the views and preferences of patients when designing guidelines. Previous studies pointed out that consideration of patient preferences could increase adherence to treatment, satisfaction with treatment, and health outcomes.[114, 115] Therefore, future guideline development should consider patient preferences as an important factor.

\section{Limitations}


First, due to the variations of reporting and expression of different CPGs, there may be some inappropriate and inaccurate interpretations of our research because there is heterogeneity in the way that CPGs are conceptualized and how their evidence and recommendations are presented. This issue is inherent. Second, for various reasons, we may fail to identify all relevant and standard-compliant documents. Third, different CPGs used different grading systems that were based on different coding systems to classify the quality of evidence and strength of recommendations. Therefore, it is hard to summarize and unify the quality of evidence for each recommendation and conduct further studies.

\section{Conclusions}

To improve the management of spinal pain, we summarized CPG recommendations to identify consensuses of management regimes. However, the recommendations of some CPGs were not very clear and specific, and they even provided inconsistent recommendations. Evidence mapping is a good tool to reduce research waste and facilitate the process of knowledge transfer. The results of our study can be used to optimize the implementation of these recommendations and to promote improvement in the development of reliable CPGs on spinal pain. We found the mean score of the application of included CPGs was the lowest and most of CPGs didn't consider patient preferences. Therefore, guideline makers should concentrate on patient preference and application in future guidelines. Once these weaknesses are resolved, a more effective and accurate management regime that will lead to reduced costs of spinal pain can be established.

\section{Declarations}

\section{Acknowledgements}

Not applicable.

\section{Contributors}

JFH, ZSQ and AMW designed the study. JFH, ZSQ and XQZ performed a systematic search of the literature. JFH, ZSQ, XQZ, JLL and KZ screened potential articles and acquired data for analysis. JFH, ZSQ, XQZ and JLL evaluated the methodological quality and performed statistical analysis and interpretation of data. JFH and ZSQ drafted the paper. YML, YXW and AMW critically revised the draft manuscript. All authors read and approved the final manuscript.

\section{Funding}

This work was supported by the National Natural Science Foundation of China (81501933), Wenzhou Municipal Science and Technology Bureau (Y20190018), Wenzhou leading talent innovative project (RX2016004). The funders had no role in the design, execution, and writing up of the study.

\section{Competing interests}

None declared.

\section{Patient consent for publication}

Not required.

\section{Ethics approval}

Ethical approval is not required for this study as it utilizes publicly available health data.

Data availability statement

Data are available upon reasonable request

\section{References}

1. Lin I, Wiles L, Waller R, Goucke R, Nagree Y, Gibberd M, Straker L, Maher CG, O'Sullivan PPB: What does best practice care for musculoskeletal pain look like? Eleven consistent recommendations from high-quality clinical practice guidelines: systematic review. Br J Sports Med 2020, 54(2):79-86.

2. Machado GC, Maher CG, Ferreira PH, Day RO, Pinheiro MB, Ferreira ML: Non-steroidal anti-inflammatory drugs for spinal pain: a systematic review and meta-analysis. Ann Rheum Dis 2017, 76(7):1269-1278.

3. Machado GC, Maher CG, Ferreira PH, Pinheiro MB, Lin CW, Day RO, McLachlan AJ, Ferreira ML: Efficacy and safety of paracetamol for spinal pain and osteoarthritis: systematic review and meta-analysis of randomised placebo controlled trials. BMJ 2015, 350:h1225.

4. Maher C, Underwood M, Buchbinder R: Non-specific low back pain. Lancet 2017, 389(10070):736-747.

5. Wu A, Dong W, Liu S, Cheung JPY, Kwan KYH, Zeng X, Zhang K, Sun Z, Wang X, Cheung KMC et al: The prevalence and years lived with disability caused by low back pain in China, 1990 to 2016: findings from the global burden of disease study 2016. Pain 2019, 160(1):237-245.

6. Global, regional, and national incidence, prevalence, and years lived with disability for 310 diseases and injuries, 1990-2015: a systematic analysis for the Global Burden of Disease Study 2015. Lancet (London, England) 2016, 388(10053):1545-1602.

7. Steel N, Ford JA, Newton JN, Davis ACJ, Vos T, Naghavi M, Glenn S, Hughes A, Dalton AM, Stockton D et al: Changes in health in the countries of the UK and 150 English Local Authority areas 1990-2016: a systematic analysis for the Global Burden of Disease Study 2016. Lancet 2018, 392(10158):1647- 
1661.

8. Hoy D, March L, Woolf A, Blyth F, Brooks P, Smith E, Vos T, Barendregt J, Blore J, Murray C et al: The global burden of neck pain: estimates from the global burden of disease 2010 study. Ann Rheum Dis 2014, 73(7):1309-1315.

9. Pinto RZ, Verwoerd AJH, Koes BW: Which pain medications are effective for sciatica (radicular leg pain)? BMJ 2017, 359 :j4248.

10. Global, regional, and national incidence, prevalence, and years lived with disability for 354 diseases and injuries for 195 countries and territories, 1990 2017: a systematic analysis for the Global Burden of Disease Study 2017. Lancet (London, England) 2018, 392(10159):1789-1858.

11. Fatoye F, Gebrye T, Odeyemi I: Real-world incidence and prevalence of low back pain using routinely collected data. Rheumatol Int 2019, 39(4):619-626.

12. Andersson GB: Epidemiological features of chronic low-back pain. Lancet 1999, 354(9178):581-585.

13. Gustafsson ML, Laaksonen C, Aromaa M, Loyttyniemi E, Salantera S: The prevalence of neck-shoulder pain, back pain and psychological symptoms in association with daytime sleepiness - a prospective follow-up study of school children aged 10 to 15. Scand J Pain 2018, 18(3):389-397.

14. Johansson MS, Jensen StochkendahI M, Hartvigsen J, Boyle E, Cassidy JD: Incidence and prognosis of mid-back pain in the general population: A systematic review. Eur J Pain 2017, 21(1):20-28.

15. Pinto RZ, Maher CG, Ferreira ML, Ferreira PH, Hancock M, Oliveira VC, McLachlan AJ, Koes B: Drugs for relief of pain in patients with sciatica: systematic review and meta-analysis. BMJ 2012, 344:e497.

16. Konstantinou K, Dunn KM: Sciatica: review of epidemiological studies and prevalence estimates. Spine (Phila Pa 1976) 2008, 33(22):2464-2472.

17. Dieleman JL, Baral R, Birger M, Bui AL, Bulchis A, Chapin A, Hamavid H, Horst C, Johnson EK, Joseph J et al: US Spending on Personal Health Care and Public Health, 1996-2013. JAMA 2016, 316(24):2627-2646.

18. Childs JD, Fritz JM, Wu SS, Flynn TW, Wainner RS, Robertson EK, Kim FS, George SZ: Implications of early and guideline adherent physical therapy for low back pain on utilization and costs. BMC Health Serv Res 2015, 15:150.

19. Rutten GM, Degen S, Hendriks EJ, Braspenning JC, Harting J, Oostendorp RA: Adherence to clinical practice guidelines for low back pain in physical therapy: do patients benefit? Phys Ther 2010, 90(8):1111-1122.

20. Jakobsen MD, Sundstrup E, Brandt M, Persson R, Andersen LL: Estimation of physical workload of the low-back based on exposure variation analysis during a full working day among male blue-collar workers. Cross-sectional workplace study. Appl Ergon 2018, 70:127-133.

21. Baiardini I, Braido F, Bonini M, Compalati E, Canonica GW: Why do doctors and patients not follow guidelines? Curr Opin Allergy Clin Immunol 2009, $9(3): 228-233$.

22. Williams MJ, Kevat DA, Loff B: Conflict of interest guidelines for clinical guidelines. Med J Aust 2011, 195(8):442-445.

23. Scott IA, Guyatt GH: Clinical practice guidelines: the need for greater transparency in formulating recommendations. Med J Aust 2011, 195(1):29-33.

24. Lin I, Wiles LK, Waller R, Goucke R, Nagree Y, Gibberd M, Straker L, Maher CG, O'Sullivan PPB: Poor overall quality of clinical practice guidelines for musculoskeletal pain: a systematic review. Br J Sports Med 2018, 52(5):337-343.

25. Miake-Lye IM, Hempel S, Shanman R, Shekelle PG: What is an evidence map? A systematic review of published evidence maps and their definitions, methods, and products. Syst Rev 2016, 5:28.

26. Chen Y, Yang K, Marušic A, Qaseem A, Meerpohl JJ, Flottorp S, AkI EA, Schünemann HJ, Chan ES, Falck-Ytter Y et al: A Reporting Tool for Practice Guidelines in Health Care: The RIGHT Statement. Ann Intern Med 2017, 166(2):128-132.

27. IOM (Institute of Medicine).Clinical practice guidelines we can trust. Washington (DC): National Academies Press 2011.

28. Brouwers MC, Kho ME, Browman GP, Burgers JS, Cluzeau F, Feder G, Fervers B, Graham ID, Grimshaw J, Hanna SE et al: AGREE II: advancing guideline development, reporting and evaluation in health care. CMAJ 2010, 182(18):E839-842.

29. Brouwers MC, Kho ME, Browman GP, Burgers JS, Cluzeau F, Feder G, Fervers B, Graham ID, Hanna SE, Makarski J et al: Development of the AGREE II, part 2: assessment of validity of items and tools to support application. CMAJ 2010, 182(10):E472-478.

30. Jiang M, Guan WJ, Fang ZF, Xie YQ, Xie JX, Chen H, Wei D, Lai KF, Zhong NS: A Critical Review of the Quality of Cough Clinical Practice Guidelines. Chest 2016, 150(4):777-788.

31. Bryans R, Decina P, Descarreaux M, Duranleau M, Marcoux H, Potter B, Ruegg RP, Shaw L, Watkin R, White E: Evidence-based guidelines for the chiropractic treatment of adults with neck pain. $J$ Manipulative Physiol Ther 2014, 37(1):42-63.

32. JD B, WGM S-P, JB S, J P, MW vT, E B, J K, G M, AP V: Clinical Practice Guideline for Physical Therapy Assessment and Treatment in Patients With Nonspecific Neck Pain. Phys Ther 2018, 98(3):162-171.

33. PR B, AR G, JM E, LL D, D C, DM W, C S, EK R: Neck Pain: Revision 2017. J Orthop Sports Phys Ther 2017, 47(7):A1-A83.

34. Kjaer P, Kongsted A, Hartvigsen J, Isenberg-Jorgensen A, Schiottz-Christensen B, Soborg B, Krog C, Moller CM, Halling CMB, Lauridsen HH et al: National clinical guidelines for non-surgical treatment of patients with recent onset neck pain or cervical radiculopathy. Eur Spine J 2017, 26(9):2242-2257.

35. Cote P, Wong JJ, Sutton D, Shearer HM, Mior S, Randhawa K, Ameis A, Carroll LJ, Nordin M, Yu H et al: Management of neck pain and associated disorders: A clinical practice guideline from the Ontario Protocol for Traffic Injury Management (OPTIMa) Collaboration. Eur Spine J 2016, 25(7):20002022.

36. Bishop FL, Dima AL, Ngui J, Little P, Moss-Morris R, Foster NE, Lewith GT: "Lovely Pie in the Sky Plans": A Qualitative Study of Clinicians' Perspectives on Guidelines for Managing Low Back Pain in Primary Care in England. Spine (Phila Pa 1976) 2015, 40(23):1842-1850.

37. Monticone M, lovine R, de Sena G, Rovere G, Uliano D, Arioli G, Bonaiuti D, Brugnoni G, Ceravolo G, Cerri C et al: The Italian Society of Physical and Rehabilitation Medicine (SIMFER) recommendations for neck pain. G Ital Med Lav Ergon 2013, 35(1):36-50. 
38. Qaseem A, Wilt TJ, McLean RM, Forciea MA, Clinical Guidelines Committee of the American College of P: Noninvasive Treatments for Acute, Subacute, and Chronic Low Back Pain: A Clinical Practice Guideline From the American College of Physicians. Ann Intern Med 2017, 166(7):514-530.

39. Cho H-W, Hwang E-H, Lim B, Heo K-H, Liu J-P, Tsutani K, Lee MS, Shin B-C: How current Clinical Practice Guidelines for low back pain reflect Traditional Medicine in East Asian Countries: a systematic review of Clinical Practice Guidelines and systematic reviews. PLoS One 2014, 9(2):e88027-e88027.

40. Van Wambeke P, Desomer A, Jonckheer P, Depreitere B: The Belgian national guideline on low back pain and radicular pain: key roles for rehabilitation, assessment of rehabilitation potential and the PRM specialist. Eur J Phys Rehabil Med 2019.

41. Bussieres AE, Stewart G, Al-Zoubi F, Decina P, Descarreaux M, Haskett D, Hincapie C, Page I, Passmore S, Srbely J et al: Spinal Manipulative Therapy and Other Conservative Treatments for Low Back Pain: A Guideline From the Canadian Chiropractic Guideline Initiative. J Manipulative Physiol Ther 2018, 41(4):265-293

42. MJ S, P K, J H, A K, J A, M A, MØ A, G F, B H, MB J et al: National Clinical Guidelines for non-surgical treatment of patients with recent onset low back pain or lumbar radiculopathy. Eur Spine $J$ 2018, 27(1):60-75.

43. HR C: [Clinical practice guideline: Non-specific low back pain]. MMW Fortschritte der Medizin 2018, 160(16):56-59.

44. Globe G, Farabaugh RJ, Hawk C, Morris CE, Baker G, Whalen WM, Walters S, Kaeser M, Dehen M, Augat T: Clinical Practice Guideline: Chiropractic Care for Low Back Pain. J Manipulative Physiol Ther 2016, 39(1):1-22.

45. JF C, B G, B K, F P, M P, SG S: Non-Specific Low Back Pain. Deutsches Arzteblatt international 2017, 114:883-890.

46. Soon J, Traeger AC, Elshaug AG, Cvejic E, Maher CG, Doust JA, Mathieson S, McCaffery K, Bonner C: Effect of two behavioural 'nudging' interventions on management decisions for low back pain: a randomised vignette-based study in general practitioners. BMJ Qual Saf 2019, 28(7):547-555.

47. Märker-Hermann E, Kiltz U, Braun J: Treatment of chronic back pain: current standards. Internist (Berl) 2014, 55(12):1410-1418.

48. Sanz Sanz J, Juanola Roura X, Seoane-Mato D, Montoro M, Gomollón F, Grupo de Trabajo del proyecto P: Screening of Inflammatory Bowel Disease and Spondyloarthritis for Referring Patients Between Rheumatology and Gastroenterology. Reumatol Clin 2018, 14(2):68-74.

49. Pangarkar SS, Kang DG, Sandbrink F, Bevevino A, Tillisch K, Konitzer L, Sall J: VAVDoD Clinical Practice Guideline: Diagnosis and Treatment of Low Back Pain. J Gen Intern Med 2019, 34(11):2620-2629.

50. Felice C, Leccese P, Scudeller L, Lubrano E, Cantini F, Castiglione F, Gionchetti P, Orlando A, Salvarani C, Scarpa R et al: Red flags for appropriate referral to the gastroenterologist and the rheumatologist of patients with inflammatory bowel disease and spondyloarthritis. Clin Exp Immunol 2019, 196(1):123138.

51. Kreiner DS, Hwang SW, Easa JE, Resnick DK, Baisden JL, Bess S, Cho CH, DePalma MJ, Dougherty P, 2nd, Fernand R et al: An evidence-based clinical guideline for the diagnosis and treatment of lumbar disc herniation with radiculopathy. Spine J 2014, 14(1):180-191.

52. Bier JD, Scholten-Peeters WGM, Staal JB, Pool J, van Tulder MW, Beekman E, Knoop J, Meerhoff G, Verhagen AP: Clinical Practice Guideline for Physical Therapy Assessment and Treatment in Patients With Nonspecific Neck Pain. Phys Ther 2018, 98(3):162-171.

53. Williams CM, Maher CG, Hancock MJ, McAuley JH, McLachlan AJ, Britt H, Fahridin S, Harrison C, Latimer J: Low back pain and best practice care: A survey of general practice physicians. Arch Intern Med 2010, 170(3):271-277.

54. Runciman WB, Hunt TD, Hannaford NA, Hibbert PD, Westbrook JI, Coiera EW, Day RO, Hindmarsh DM, McGlynn EA, Braithwaite J: CareTrack: assessing the appropriateness of health care delivery in Australia. Med J Aust 2012, 197(2):100-105.

55. Babatunde OO, Jordan JL, Van der Windt DA, Hill JC, Foster NE, Protheroe J: Effective treatment options for musculoskeletal pain in primary care: A systematic overview of current evidence. PLoS One 2017, 12(6):e0178621.

56. Cohen SP, Hooten WM: Advances in the diagnosis and management of neck pain. BMJ 2017, 358:j3221.

57. JWS V, CG M, K W, J VZ, CB M, L D, MC B, M G, B K, SJ L: Low back pain. Nature reviews Disease primers 2018, 4(1):52.

58. Maher C, Underwood M, Buchbinder R: Non-specific low back pain. Lancet 2017.

59. Sterling M, de Zoete RMJ, Coppieters I, Farrell SF: Best Evidence Rehabilitation for Chronic Pain Part 4: Neck Pain. J Clin Med 2019.

60. Jensen RK, Kongsted A, Kjaer P, Koes B: Diagnosis and treatment of sciatica. BMJ 2019.

61. Pinto RZ, Maher CG, Ferreira ML, Hancock M, Oliveira VC, McLachlan AJ, Koes B, Ferreira PH: Epidural corticosteroid injections in the management of sciatica: a systematic review and meta-analysis. Ann Intern Med 2012.

62. Williams CM, Maher CG, Hancock MJ, McAuley JH, McLachlan AJ, Britt H, Fahridin S, Harrison C, Latimer J: Low back pain and best practice care: A survey of general practice physicians. Arch Intern Med 2010.

63. Tan A, Zhou J, Kuo Y-F, Goodwin JS: Variation among Primary Care Physicians in the Use of Imaging for Older Patients with Acute Low Back Pain. J Gen Intern Med 2016.

64. Schlemmer E, Mitchiner JC, Brown M, Wasilevich E: Imaging during low back pain ED visits: a claims-based descriptive analysis. Am J Emerg Med 2015.

65. Rosenberg A, Agiro A, Gottlieb M, Barron J, Brady P, Liu Y, Li C, DeVries A: Early Trends Among Seven Recommendations From the Choosing Wisely Campaign. JAMA Intern Med 2015.

66. Jame SZB, Sari AA, Majdzadeh R, Rashidian A, Arab M, Rahmani H: The extent of inappropriate use of magnetic resonance imaging in low back pain and its contributory factors. Int J Prev Med 2014.

67. Overas CK, Villumsen M, Axen I, Cabrita M, Leboeuf-Yde C, Hartvigsen J, Mork PJ: Association between objectively measured physical behaviour and neckand/or low back pain: A systematic review. Eur J Pain 2020.

68. H A, M M, E S, JR Z, D S: The association between physical activity and low back pain: a systematic review and meta-analysis of observational studies. Scientific reports 2019, 9(1):8244.

Page 10/20 
69. Ebell MH, Grad R: Top 20 Research Studies of 2016 for Primary Care Physicians. Am Fam Physician 2017, 95(9):572-579.

70. Kim R, Wiest C, Clark K, Cook C, Horn M: Identifying risk factors for firstepisode neck pain: A systematic review. Musculoskelet Sci Pract 2018, 33:77-83.

71. Jun D, Zoe M, Johnston V, O'Leary S: Physical risk factors for developing non-specific neck pain in office workers: a systematic review and meta-analysis. Int Arch Occup Environ Health 2017, 90(5):373-410.

72. Sitthipornvorakul E, Janwantanakul P, Purepong N, Pensri P, van der Beek AJ: The association between physical activity and neck and low back pain: a systematic review. European Spine Journal 2010, 20(5):677-689.

73. Hallman DM, Birk Jorgensen M, Holtermann A: Objectively measured physical activity and 12-month trajectories of neck-shoulder pain in workers: A prospective study in DPHACTO. Scand J Public Health 2017, 45(3):288-298.

74. $\mathrm{DM} \mathrm{H}, \mathrm{N} \mathrm{G}, \mathrm{M} \mathrm{H}, \mathrm{SE} \mathrm{M}, \mathrm{M} \mathrm{K}, \mathrm{MB}$ J, A H: Is prolonged sitting at work associated with the time course of neck-shoulder pain? A prospective study in Danish blue-collar workers. BMJ Open 2016, 6(11):e012689.

75. Brazilian Medical A, Silvinato A, Simões RS, Buzzini RF, Bernardo WM: Lumbar herniated disc treatment with percutaneous hydrodiscectomy. Rev Assoc Med Bras (1992) 2018, 64(9):778-782.

76. LK L, M K, S K, KB V: Associations of objectively measured sitting and standing with low-back pain intensity: a 6-month follow-up of construction and healthcare workers. Scandinavian journal of work, environment \& health 2017, 43(3):269-278.

77. Malfliet A, Ickmans K, Huysmans E, Coppieters I, Willaert W, Bogaert WV, Rheel E, Bilterys T, Wilgen PV, Nijs J: Best Evidence Rehabilitation for Chronic Pain Part 3: Low Back Pain. J Clin Med 2019.

78. Gross A, Langevin P, Burnie SJ, Bédard-Brochu M-S, Empey B, Dugas E, Faber-Dobrescu M, Andres C, Graham N, Goldsmith CH et al: Manipulation and mobilisation for neck pain contrasted against an inactive control or another active treatment. Cochrane Database Syst Rev 2015.

79. Beltran-Alacreu H, López-de-Uralde-Villanueva I, Fernández-Carnero J, La Touche R: Manual Therapy, Therapeutic Patient Education, and Therapeutic Exercise, an Effective Multimodal Treatment of Nonspecific Chronic Neck Pain: A Randomized Controlled Trial. American journal of physical medicine \& rehabilitation 2015, 94(10 Suppl 1):887-897.

80. Celenay ST, Akbayrak T, Kaya DO: A Comparison of the Effects of Stabilization Exercises Plus Manual Therapy to Those of Stabilization Exercises Alone in Patients With Nonspecific Mechanical Neck Pain: A Randomized Clinical Trial. J Orthop Sports Phys Ther 2016, 46(2):44-55.

81. Fredin K, Lorås H: Manual therapy, exercise therapy or combined treatment in the management of adult neck pain - A systematic review and metaanalysis. Musculoskelet Sci Pract 2017, 31:62-71.

82. Domingues L, Pimentel-Santos FM, Cruz EB, Sousa AC, Santos A, Cordovil A, Correia A, Torres LS, Silva A, Branco PS et al: Is a combined programme of manual therapy and exercise more effective than usual care in patients with non-specific chronic neck pain? A randomized controlled trial. Clinical rehabilitation 2019, 33(12):1908-1918.

83. Palmlöf L, Holm LW, Alfredsson L, Skillgate E: Expectations of recovery: A prognostic factor in patients with neck pain undergoing manual therapy treatment. Eur J Pain 2016, 20(9):1384-1391.

84. Rubinstein SM, van Middelkoop M, Assendelft WJ, de Boer MR, van Tulder MW: Spinal manipulative therapy for chronic low-back pain. Cochrane Database Syst Rev 2011.

85. Franke H, Franke JD, Fryer G: Osteopathic manipulative treatment for nonspecific low back pain: a systematic review and meta-analysis. $B M C$ Musculoskelet Disord 2014, 15:286.

86. Chou R, Deyo R, Friedly J, Skelly A, Hashimoto R, Weimer M, Fu R, Dana T, Kraegel P, Griffin J et al: AHRQ Comparative Effectiveness Reviews. In: Noninvasive Treatments for Low Back Pain. edn. Rockville (MD): Agency for Healthcare Research and Quality (US); 2016.

87. Ruddock JK, Sallis H, Ness A, Perry RE: Spinal Manipulation Vs Sham Manipulation for Nonspecific Low Back Pain: A Systematic Review and Metaanalysis. Journal of chiropractic medicine 2016, 15(3):165-183.

88. Rubinstein SM, de Zoete A, van Middelkoop M, Assendelft WJJ, de Boer MR, van Tulder MW: Benefits and harms of spinal manipulative therapy for the treatment of chronic low back pain: systematic review and meta-analysis of randomised controlled trials. BMJ 2019, 364:1689.

89. Berman BM, Langevin HM, Witt CM, Dubner R: Acupuncture for chronic low back pain. N Engl J Med 2010, 363(5):454-461.

90. Trinh K, Graham N, Irnich D, Cameron ID, Forget M, Trinh K: Acupuncture for neck disorders. Cochrane Database Syst Rev 2016(5):CD004870.

91. M F, PH F: Acupuncture for sciatica and a comparison with Western Medicine (PEDro synthesis). Br J Sports Med 2017, 51(6):539-540.

92. Chou R, Huffman LH, Society AP, Physicians ACo: Medications for acute and chronic low back pain: a review of the evidence for an American Pain Society/American College of Physicians clinical practice guideline. Ann Intern Med 2007.

93. Enthoven WTM, Roelofs PD, Koes BW: NSAIDs for Chronic Low Back Pain. JAMA 2017.

94. Abdel Shaheed C, Maher CG, Williams KA, McLachlan AJ: Efficacy and tolerability of muscle relaxants for low back pain: Systematic review and metaanalysis. Eur J Pain 2017.

95. Weng C, Xu J, Wang Q, Lu W, Liu Z: Efficacy and Safety of Duloxetine in Osteoarthritis or Chronic Low Back Pain: A Systematic Review and Meta-analysis. Osteoarthr Cartil 2020.

96. Skljarevski V, Desaiah D, Liu-Seifert H, Zhang Q, Chappell AS, Detke MJ, lyengar S, Atkinson JH, Backonja M: Efficacy and safety of duloxetine in patients with chronic low back pain. Spine (Phila Pa 1976) 2010.

97. Deyo RA, Von Korff M, Duhrkoop D: Opioids for low back pain. BMJ 2015.

98. Rasmussen-Barr E, Held U, Grooten WJ, Roelofs PD, Koes BW, van Tulder MW, Wertli MM: Non-steroidal anti-inflammatory drugs for sciatica. Cochrane Database Syst Rev 2016.

Page $11 / 20$ 
99. Pinto RZ, Maher CG, Ferreira ML, Ferreira PH, Hancock M, Oliveira VC, McLachlan AJ, Koes B: Drugs for relief of pain in patients with sciatica: systematic review and meta-analysis. BMJ 2012.

100. Pinto RZ, Verwoerd AJH, Koes BW: Which pain medications are effective for sciatica (radicular leg pain)? BMJ 2017.

101. Schukro RP, Oehmke MJ, Geroldinger A, Heinze G, Kress H-G, Pramhas S: Efficacy of Duloxetine in Chronic Low Back Pain with a Neuropathic Component: A Randomized, Double-blind, Placebo-controlled Crossover Trial. Anesthesiology 2016.

102. Vanelderen P, Van Zundert J, Kozicz T, Puylaert M, De Vooght P, Mestrum R, Heylen R, Roubos E, Vissers K: Effect of minocycline on lumbar radicular neuropathic pain: a randomized, placebo-controlled, double-blind clinical trial with amitriptyline as a comparator. Anesthesiology 2015.

103. Brötz D, Maschke E, Burkard S, Engel C, Mänz C, Ernemann U, Wick W, Weller M: Is there a role for benzodiazepines in the management of lumbar disc prolapse with acute sciatica? Pain 2010.

104. Khoromi S, Cui L, Nackers L, Max MB: Morphine, nortriptyline and their combination vs. placebo in patients with chronic lumbar root pain. Pain 2007.

105. Machado GC, Maher CG, Ferreira PH, Pinheiro MB, Lin C-WC, Day RO, McLachlan AJ, Ferreira ML: Efficacy and safety of paracetamol for spinal pain and osteoarthritis: systematic review and meta-analysis of randomised placebo controlled trials. BMJ 2015.

106. Abdel Shaheed C, Maher CG, Williams KA, Day R, McLachlan AJ: Efficacy, Tolerability, and Dose-Dependent Effects of Opioid Analgesics for Low Back Pain: A Systematic Review and Meta-analysis. JAMA Intern Med 2016.

107. Brosseau L, Wells GA, Poitras S, Tugwell P, Casimiro L, Novikov M, Loew L, Sredic D, Clément S, Gravelle A et al: Ottawa Panel evidence-based clinical practice guidelines on therapeutic massage for low back pain. Journal of bodywork and movement therapies 2012, 16(4):424-455.

108. Childs JD, Cleland JA, Elliott JM, Teyhen DS, Wainner RS, Whitman JM, Sopky BJ, Godges JJ, Flynn TW: Neck pain: Clinical practice guidelines linked to the International Classification of Functioning, Disability, and Health from the Orthopedic Section of the American Physical Therapy Association. $J$ Orthop Sports Phys Ther 2008, 38(9):A1-a34.

109. Ransohoff DF, Pignone M, Sox HC: How to decide whether a clinical practice guideline is trustworthy. JAMA 2013, 309(2):139-140.

110. Wong JJ, Côté P, Sutton DA, Randhawa K, Yu H, Varatharajan S, Goldgrub R, Nordin M, Gross DP, Shearer HM et al: Clinical practice guidelines for the noninvasive management of low back pain: A systematic review by the Ontario Protocol for Traffic Injury Management (OPTIMa) Collaboration. Eur $J$ Pain 2017, 21(2):201-216.

111. Kosloff TM, Elton D, Shulman SA, Clarke JL, Skoufalos A, Solis A: Conservative spine care: opportunities to improve the quality and value of care. Population health management 2013, 16(6):390-396.

112. Boivin A, Currie K, Fervers B, Gracia J, James M, Marshall C, Sakala C, Sanger S, Strid J, Thomas V et al: Patient and public involvement in clinical guidelines: international experiences and future perspectives. Quality \& safety in health care 2010, 19(5):e22.

113. Verkerk K, Van Veenendaal H, Severens JL, Hendriks EJ, Burgers JS: Considered judgement in evidence-based guideline development. International journal for quality in health care : journal of the International Society for Quality in Health Care 2006, 18(5):365-369.

114. Brazier JE, Dixon S, Ratcliffe J: The role of patient preferences in costeffectiveness analysis: a conflict of values? Pharmacoeconomics 2009, 27(9):705712.

115. Dirksen CD, Utens CM, Joore MA, van Barneveld TA, Boer B, Dreesens DH, van Laarhoven H, Smit C, Stiggelbout AM, van der Weijden T: Integrating evidence on patient preferences in healthcare policy decisions: protocol of the patient-VIP study. Implement Sci 2013, 8:64.

\section{Tables}

Table 1. General characteristics of included guidelines 


\begin{tabular}{|c|c|c|c|c|}
\hline Title & $\begin{array}{l}\text { Country and year of } \\
\text { publication }\end{array}$ & Organization & Type of organization & Grading system \\
\hline \multicolumn{5}{|l|}{$\begin{array}{l}\text { Neck } \\
\text { pain }\end{array}$} \\
\hline Canada & Canada, 2013 & Guidelines Development Committee (GDC) & $\begin{array}{l}\text { Guideline developer } \\
\text { organization }\end{array}$ & $\begin{array}{l}\text { Cochrane Back Review } \\
\text { Group (CBRG) }\end{array}$ \\
\hline KNGF & Netherlands,2018 & The Royal Dutch Society for Physical Therapy (KNGF) & $\begin{array}{l}\text { Medical specialty } \\
\text { society }\end{array}$ & KNGF \\
\hline APTA & USA, 2017 & $\begin{array}{l}\text { Orthopaedic Section of the American Physical Therapy } \\
\text { Association }\end{array}$ & $\begin{array}{l}\text { Medical specialty } \\
\text { society }\end{array}$ & GRADE \\
\hline DHA & Denmark, 2017 & Danish Health Authority (DHA) & Governmental body & GRADE \\
\hline OPTIMa & Canada, 2016 & $\begin{array}{l}\text { Ontario Protocol for Traffic Injury Management (OPTIMa) } \\
\text { Collaboration }\end{array}$ & Governmental body & OPTIMa \\
\hline Scottish & Scottish, 2019 & Scottish Intercollegiate Guidelines Network (SIGN) & Governmental body & SIGN \\
\hline SIMFER & Italy, 2015 & $\begin{array}{l}\text { The Italian Society of Physical and Rehabilitation Medicine } \\
\text { (SIMFER) }\end{array}$ & $\begin{array}{l}\text { Medical specialty } \\
\text { society }\end{array}$ & SIMFER \\
\hline \multicolumn{5}{|l|}{$\begin{array}{l}\text { Low } \\
\text { back } \\
\text { pain }\end{array}$} \\
\hline ACP & USA, 2017 & American College of Physicians & $\begin{array}{l}\text { Medical specialty } \\
\text { society }\end{array}$ & ACP \\
\hline $\mathrm{ACl}$ & Australia,2016 & The Agency for Clinical Innovation & $\begin{array}{l}\text { Medical specialty } \\
\text { society }\end{array}$ & $\mathrm{ACl}$ \\
\hline Belgium & Belgium, 2019 & Belgian Health Care Knowledge Centre (KCE) & $\begin{array}{l}\text { Medical specialty } \\
\text { society }\end{array}$ & GRADE \\
\hline Canada & Canada, 2017 & Canadian Chiropractic Guideline Initiative (CCGI) & $\begin{array}{l}\text { Guideline developer } \\
\text { organization }\end{array}$ & GRADE \\
\hline $\mathrm{DHA}$ & Denmark, 2017 & Danish Health Authority (DHA) & $\begin{array}{l}\text { Medical specialty } \\
\text { society }\end{array}$ & GRADE \\
\hline German & German, 2018 & $\begin{array}{l}\text { German Migraine and Headache Society and the German Pain } \\
\text { Society }\end{array}$ & $\begin{array}{l}\text { Medical specialty } \\
\text { society }\end{array}$ & None \\
\hline $\begin{array}{l}\text { Globe et } \\
\text { al. }\end{array}$ & USA, 2016 & Chiropractic Guidelines and Practice Parameters (CCGPP) & $\begin{array}{l}\text { Guideline developer } \\
\text { organization }\end{array}$ & $\begin{array}{l}\text { RAND-UCLA } \\
\text { methodology }\end{array}$ \\
\hline NDMG & German, 2017 & German Disease Management Guideline (NDMG) & $\begin{array}{l}\text { Medical specialty } \\
\text { society }\end{array}$ & NDMG \\
\hline KNGF & Netherlands,2013 & $\begin{array}{l}\text { Royal Dutch Society for Physical Therapy (Koninklijk Nederlands } \\
\text { Genootschap voor Fysiotherapie) }\end{array}$ & $\begin{array}{l}\text { Medical specialty } \\
\text { society }\end{array}$ & KNGF \\
\hline Scottish & Scottish, 2019 & Scottish Intercollegiate Guidelines Network (SIGN) & Governmental body & SIGN \\
\hline Colorado & USA, 2014 & $\begin{array}{l}\text { Department of Labor and Employment DIVISION OF WORKERS' } \\
\text { COMPENSATION }\end{array}$ & Governmental body & None \\
\hline TOP & Canada,2017 & Institute of health economics & $\begin{array}{l}\text { Medical specialty } \\
\text { society }\end{array}$ & None \\
\hline VA/DoD & USA, 2019 & $\begin{array}{l}\text { U.S. Department of Veterans Affairs (VA) and U.S. Department of } \\
\text { Defense (DoD) }\end{array}$ & Governmental body & VA/DoD \\
\hline NICE & UK, 2018 & National Institute for Health and Care Excellence (NICE) & $\begin{array}{l}\text { Medical specialty } \\
\text { society }\end{array}$ & NICE \\
\hline \multicolumn{5}{|l|}{ Sciatica } \\
\hline DHA & Denmark, 2017 & Danish Health Authority (DHA) & $\begin{array}{l}\text { Medical specialty } \\
\text { society }\end{array}$ & GRADE \\
\hline NASS & USA, 2013 & North American Spine Society (NASS) & $\begin{array}{l}\text { Medical specialty } \\
\text { society }\end{array}$ & NASS \\
\hline NICE & UK, 2018 & National Institute for Health and Care Excellence (NICE) & $\begin{array}{l}\text { Medical specialty } \\
\text { society }\end{array}$ & NICE \\
\hline
\end{tabular}

GRADE: Grading of Recommendations Assessment, Development and Evaluation; KNGF: The Royal Dutch Society for Physical Therapy; APTA: Orthopaedic Section of the American Physical Therapy Association; DHA: Danish Health Authority; OPTIMa: Ontario Protocol for Traffic Injury Management Collaboration; SIGN: Scottish Intercollegiate Guidelines Network; SIMFER: The Italian Society of Physical and Rehabilitation Medicine; ACP: American College of Physicians; ACl: The Agency for Clinical Innovation; NDMG: German Disease Management Guideline; KNGF: Koninklijk Nederlands Genootschap voor 
Fysiotherapie; TOP: Toward Optimized Practice; VA/DoD: U.S. Department of Veterans Affairs (VA) and U.S. Department of Defense (DoD); NICE: National Institute for Health and Care Excellence; NASS: North American Spine Society

\begin{tabular}{|c|c|c|c|c|c|c|c|c|c|c|c|c|c|c|}
\hline & \multicolumn{5}{|l|}{ Neck pain } & \multicolumn{9}{|c|}{ Low back pain } \\
\hline & Canada & KNGF & APTA & DHA & OPTIMa & Scottish & SIMFER & ACP & ACI & Belgium & Canada & DHA & German & Dutch \\
\hline Domain 1: Basic information & $5(83.33 \%)$ & $6(100.00 \%)$ & $5(83.33 \%)$ & $6(100.00 \%)$ & $6(100.00 \%)$ & $6(100.00 \%)$ & $4(67.67 \%)$ & $4(67.67 \%)$ & $6(100.00 \%)$ & $5(83.33 \%)$ & $5(83.33 \%)$ & $6(100.00 \%)$ & $4(67.67 \%)$ & $5(83.33 \%)$ \\
\hline Domain 2: Background & $6(75.00 \%)$ & $7(87.50 \%)$ & $5(62.50 \%)$ & $8(100.00 \%)$ & $8(100.00 \%)$ & $8(100.00 \%)$ & $2(25.00 \%)$ & $8(100.00 \%)$ & $6(75.00 \%)$ & $5(62.50 \%)$ & $6(75.00 \%)$ & $8(100.00 \%)$ & $3(37.50 \%)$ & $5(62.50 \%)$ \\
\hline Domain 3: Evidence & $4(80.00 \%)$ & $2(40.00 \%)$ & $4(80.00 \%)$ & $5(100.00 \%)$ & $4(80.00 \%)$ & $5(100.00 \%)$ & $0(0 \%)$ & $5(100.00 \%)$ & $2(40.00 \%)$ & $1(20.00 \%)$ & $5(100.00 \%)$ & $5(100.00 \%)$ & $0(0 \%)$ & $4(80.00 \%)$ \\
\hline Domain 4: Recommendations & $3(42.86 \%)$ & $3(42.86 \%)$ & $4(57.14 \%)$ & $6(85.71 \%)$ & $5(71.43 \%)$ & $7(100 \%)$ & $1(14.29 \%)$ & $5(71.43 \%)$ & $4(57.14 \%)$ & $2(28.57 \%)$ & $6(85.71 \%)$ & $6(85.71 \%)$ & $2(28.57 \%)$ & $2(28.57 \%)$ \\
\hline $\begin{array}{l}\text { Domain 5: Review and quality } \\
\text { assurance }\end{array}$ & $0(0 \%)$ & $1(50.00 \%)$ & $1(50.00 \%)$ & $2(100.00 \%)$ & $2(100.00 \%)$ & $2(100.00 \%)$ & $0(0 \%)$ & $2(100.00 \%)$ & $2(100.00 \%)$ & $0(0 \%)$ & $2(100.00 \%)$ & $2(100.00 \%)$ & $0(0 \%)$ & $0(0 \%)$ \\
\hline $\begin{array}{l}\text { Domain 6: Funding, declaration } \\
\text { and management of interest }\end{array}$ & $2(50.00 \%)$ & $4(100.00 \%)$ & $2(50.00 \%)$ & $4(100.00 \%)$ & $3(75.00 \%)$ & $3(75.00 \%)$ & $0(0 \%)$ & $3(75.00 \%)$ & $0(0 \%)$ & $0(0 \%)$ & $4(100.00 \%)$ & $4(100.00 \%)$ & $0(0 \%)$ & $0(0 \%)$ \\
\hline Domain 7: Other information & $2(66.67 \%)$ & $3(100.00 \%)$ & $2(66.67 \%)$ & $3(100.00 \%)$ & $3(100.00 \%)$ & $3(100.00 \%)$ & $1(33.33 \%)$ & $1(33.33 \%)$ & $2(66.67 \%)$ & $2(66.67 \%)$ & $3(100.00 \%)$ & $3(100.00 \%)$ & $1(33.33 \%)$ & $3(100.00 \%)$ \\
\hline Number of reported items & 22 & 26 & 22 & 34 & 31 & 34 & 8 & 28 & 22 & 15 & 30 & 34 & 10 & 19 \\
\hline
\end{tabular}

Table 2. continued
\begin{tabular}{|l|l|l|l|l|l|l|l|l|l|l|}
\hline Low back pain & \multicolumn{1}{l|l|}{$l \mid$} \\
\hline Globe et al. & NDMG & KNGF & Scottish & Colorado & TOP & VA/DoD & NICE & DHA & NASS & NICE \\
\hline $5(83.33 \%)$ & $3(50.00 \%)$ & $6(100.00 \%)$ & $6(100.00 \%)$ & $3(50.00 \%)$ & $5(83.33 \%)$ & $6(100.00 \%)$ & $6(100.00 \%)$ & $6(100.00 \%)$ & $4(67.67 \%)$ & $6(100.00 \%)$ \\
\hline $6(75.00 \%)$ & $5(62.50 \%)$ & $7(87.50 \%)$ & $8(100.00 \%)$ & $4(50.00 \%)$ & $4(50.00 \%)$ & $5(62.50 \%)$ & $8(100.00 \%)$ & $8(100.00 \%)$ & $4(50.00 \%)$ & $8(100.00 \%)$ \\
\hline $5(100.00 \%)$ & $1(20.00 \%)$ & $2(40.00 \%)$ & $5(100.00 \%)$ & $0(0 \%)$ & $0(0 \%)$ & $3(60.00 \%)$ & $5(100.00 \%)$ & $5(100.00 \%)$ & $3(60.00 \%)$ & $5(100.00 \%)$ \\
\hline $3(42.86 \%)$ & $2(28.57 \%)$ & $3(42.86 \%)$ & $7(100 \%)$ & $3(42.86 \%)$ & $5(71.43 \%)$ & $7(100 \%)$ & $7(100 \%)$ & $6(85.71 \%)$ & $5(71.43 \%)$ & $7(100 \%)$ \\
\hline $1(50.00 \%)$ & $0(0 \%)$ & $1(50.00 \%)$ & $2(100.00 \%)$ & $0(0 \%)$ & $0(0 \%)$ & $0(0 \%)$ & $2(100.00 \%)$ & $2(100.00 \%)$ & $2(100.00 \%)$ & $2(100.00 \%)$ \\
\hline $2(50.00 \%)$ & $1(25.00 \%)$ & $4(100.00 \%)$ & $3(75.00 \%)$ & $0(0 \%)$ & $0(0 \%)$ & $2(50.00 \%)$ & $3(75.00 \%)$ & $4(100.00 \%)$ & $2(50.00 \%)$ & $3(75.00 \%)$ \\
\hline $3(100.00 \%)$ & $1(33.33 \%)$ & $3(100.00 \%)$ & $3(100.00 \%)$ & $1(33.33 \%)$ & $1(33.33 \%)$ & $2(66.67 \%)$ & $3(100.00 \%)$ & $3(100.00 \%)$ & $1(33.33 \%)$ & $3(100.00 \%)$ \\
\hline 25 & 12 & 26 & 34 & 11 & 15 & 25 & 34 & 34 & 21 & 34 \\
\hline
\end{tabular}

Table 3. Review of recommendations for the management of spinal pain 


\begin{tabular}{|c|c|c|c|c|c|c|c|c|c|c|c|c|c|}
\hline & \multicolumn{7}{|c|}{ Neck pain } & \multicolumn{6}{|c|}{ Low back pain } \\
\hline & Canada & KNGF & APTA & DHA & OPTIMa & Scottish & SIMFER & ACP & $\mathrm{ACl}$ & Belgium & Canada & DHA & German \\
\hline \multicolumn{14}{|l|}{ Management principle } \\
\hline Patient-centered care & $\checkmark \checkmark$ & $\checkmark \checkmark$ & $\checkmark \checkmark$ & $\checkmark \checkmark$ & $\checkmark \checkmark$ & $\checkmark \checkmark$ & $\checkmark \checkmark$ & $\checkmark \checkmark$ & $\checkmark \checkmark$ & $\checkmark \checkmark$ & $\checkmark \checkmark$ & $\checkmark \checkmark$ & $\checkmark \checkmark$ \\
\hline \multicolumn{14}{|l|}{ Assessment } \\
\hline $\begin{array}{l}\text { Diagnosis: exclude } \\
\text { serious pathology }\end{array}$ & & $\checkmark \checkmark$ & $\checkmark \checkmark$ & & $\checkmark \checkmark$ & $\checkmark \checkmark$ & $\checkmark \checkmark$ & & $\checkmark \checkmark$ & $\checkmark \checkmark$ & $\checkmark \checkmark$ & & $\checkmark \checkmark$ \\
\hline $\begin{array}{l}\text { Diagnosis: classify neck } \\
\text { pain grades I-IV }\end{array}$ & & $\checkmark \checkmark$ & & & $\checkmark \checkmark$ & & & & & & & & \\
\hline $\begin{array}{l}\text { Diagnosis: classify } \\
\text { acute, sub-acute and } \\
\text { chronic pain }\end{array}$ & $\checkmark \checkmark$ & & $\checkmark \checkmark$ & & & $\checkmark \checkmark$ & $\checkmark \checkmark$ & $\checkmark \checkmark$ & & & $\checkmark \checkmark$ & & \\
\hline $\begin{array}{l}\text { Use electrodiagnostic } \\
\text { and neuromuscular } \\
\text { testing for feedback }\end{array}$ & & & & & & $\checkmark \checkmark$ & & $\checkmark \checkmark$ & & & & & \\
\hline $\begin{array}{l}\text { Assess psychosocial } \\
\text { factors }\end{array}$ & & $\checkmark \checkmark$ & & & $\checkmark \checkmark$ & $\checkmark \checkmark$ & & & $\checkmark \checkmark$ & $\checkmark \checkmark$ & $\checkmark \checkmark$ & $\checkmark \checkmark$ & $\checkmark \checkmark$ \\
\hline $\begin{array}{l}\text { Routine use of } \\
\text { radiological imaging }\end{array}$ & & & & & & & $x$ & & $x$ & $x$ & $x$ & $x$ & $x$ \\
\hline $\begin{array}{l}\text { Undertake physical } \\
\text { examination }\end{array}$ & & $\checkmark \checkmark$ & $\checkmark \checkmark$ & & & $\checkmark \checkmark$ & $\checkmark \checkmark$ & & $\checkmark \checkmark$ & $\checkmark \checkmark$ & $\checkmark \checkmark$ & & \\
\hline $\begin{array}{l}\text { Evaluation/re-evaluation } \\
\text { and measurement }\end{array}$ & & $\checkmark \checkmark$ & $\checkmark \checkmark$ & & $\checkmark \checkmark$ & & & & $\checkmark \checkmark$ & & $\checkmark \checkmark$ & & $\checkmark \checkmark$ \\
\hline \multicolumn{14}{|l|}{ Non-Pharmacotherapy } \\
\hline $\begin{array}{l}\text { Provide } \\
\text { education/information }\end{array}$ & $\checkmark \checkmark$ & $\checkmark$ & $\checkmark \checkmark$ & $\checkmark \checkmark$ & $\checkmark \checkmark$ & $\checkmark \checkmark$ & $?$ & & $\checkmark \checkmark$ & $\checkmark \checkmark$ & $\checkmark$ & $\checkmark$ & $\checkmark$ \\
\hline $\begin{array}{l}\text { Prescribe physical } \\
\text { activity/exercise }\end{array}$ & $\checkmark \checkmark$ & $\checkmark \checkmark$ & $\checkmark \checkmark$ & $\checkmark$ & $\checkmark$ & $\checkmark \checkmark$ & $\checkmark \checkmark$ & $\checkmark \checkmark$ & $\checkmark \checkmark$ & $\checkmark \checkmark$ & $\checkmark$ & $\checkmark$ & $\checkmark \checkmark$ \\
\hline Manual Therapy & $\checkmark \checkmark$ & $\checkmark \checkmark$ & $\checkmark \checkmark$ & $\checkmark$ & $\checkmark$ & $\checkmark$ & $\checkmark \checkmark$ & $\checkmark \checkmark$ & & $\checkmark$ & & $\checkmark$ & $?$ \\
\hline $\begin{array}{l}\text { If used, use manual } \\
\text { therapy with other } \\
\text { modalities }\end{array}$ & $\checkmark \checkmark$ & $\checkmark \checkmark$ & $\checkmark \checkmark$ & $\checkmark$ & $\checkmark$ & $\checkmark$ & $\checkmark \checkmark$ & & & $\checkmark \checkmark$ & & $\checkmark \checkmark$ & \\
\hline $\begin{array}{l}\text { Manipulation and } \\
\text { mobilization }\end{array}$ & $\checkmark \checkmark$ & $\checkmark \checkmark$ & $\checkmark \checkmark$ & & $\checkmark$ & & $\checkmark \checkmark$ & & & & & & $?$ \\
\hline Massage & $\checkmark \checkmark$ & $\checkmark$ & & $x$ & $x$ & & $\checkmark \checkmark$ & $\checkmark \checkmark$ & & & & & $x$ \\
\hline $\begin{array}{l}\text { Electrotherapy including } \\
\text { Transcutaneous Nerve } \\
\text { Stimulation }\end{array}$ & $?$ & $x$ & & & $x$ & $\checkmark$ & $\checkmark \checkmark$ & $\checkmark \checkmark$ & $x$ & $x$ & & & $x$ \\
\hline Traction & $?$ & $x$ & $\checkmark \checkmark$ & $\checkmark$ & $x$ & प & $\square$ & 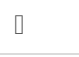 & & $x$ & & & $x$ \\
\hline Psychological therapy & & $\checkmark$ & & & $x$ & $\checkmark \checkmark$ & & $\checkmark \checkmark$ & $\checkmark \checkmark$ & $\checkmark$ & & $\checkmark$ & \\
\hline Acupuncture & & $x$ & & $x$ & $x$ & & $\checkmark \checkmark$ & $\checkmark \checkmark$ & & $?$ & & $x$ & $?$ \\
\hline Ultrasound & & $x$ & & & & & $\checkmark \checkmark$ & & & $x$ & & & $x$ \\
\hline Passive strategies & & & & & & & & & & $x$ & & & $x$ \\
\hline $\begin{array}{l}\text { Braces/cervical } \\
\text { collar/lumbar } \\
\text { supports/belts/other } \\
\text { medical aids }\end{array}$ & & $\checkmark$ & $\checkmark$ & & $x$ & & $?$ & & & $x$ & & & \\
\hline Multimodal care & & & & & $\checkmark$ & & $\checkmark \checkmark$ & $\checkmark \checkmark$ & & & $\checkmark \checkmark$ & & $\checkmark \checkmark$ \\
\hline $\begin{array}{l}\text { Offer self-management } \\
\text { programs }\end{array}$ & & & & & & $\checkmark \checkmark$ & & & & & & & \\
\hline Bed rest & & & & & & & & & & & & & $x$ \\
\hline Heat/cold therapy & & & & & & & & $\checkmark \checkmark$ & & & & & $\checkmark$ \\
\hline \multicolumn{14}{|l|}{ Pharmacotherapy } \\
\hline Paracetamol & & & & [ & $x$ & & $\checkmark \checkmark$ & & $\checkmark \checkmark$ & $x$ & & $x$ & $?$ \\
\hline
\end{tabular}

Page 15/20 


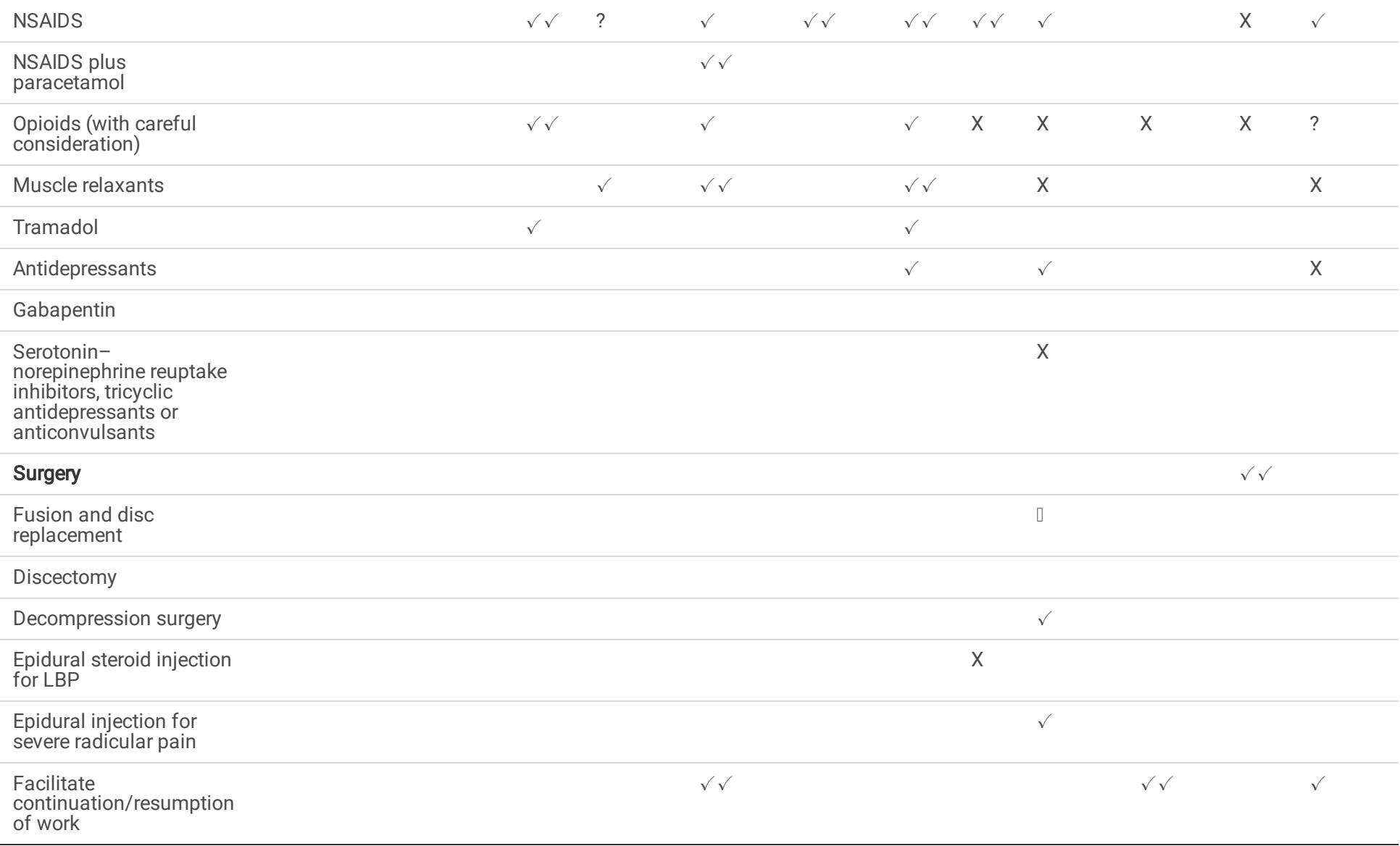

$\checkmark \checkmark$ recommended to do; $\checkmark$ could be considered to do; X do not recommend to do; \uncertain/unclear. 


\begin{tabular}{|c|c|c|c|c|c|c|c|c|}
\hline \multicolumn{9}{|c|}{ Table 3. continued } \\
\hline \multicolumn{6}{|c|}{ Low back pain } & \multicolumn{3}{|c|}{ Sciatica } \\
\hline KNGF & Scottish & Colorado & TOP & VA/DoD & NICE & DHA & NASS & NICE \\
\hline$\checkmark \checkmark$ & $\checkmark \checkmark$ & $\checkmark \checkmark$ & $\checkmark \checkmark$ & $\checkmark \checkmark$ & $\checkmark \checkmark$ & $\checkmark \checkmark$ & $\checkmark \checkmark$ & $\checkmark \checkmark$ \\
\hline \multirow[t]{3}{*}{$\checkmark \checkmark$} & $\checkmark \checkmark$ & $\checkmark \checkmark$ & $\checkmark \checkmark$ & $\checkmark \checkmark$ & $\checkmark \checkmark$ & & $\checkmark \checkmark$ & $\checkmark \checkmark$ \\
\hline & $\checkmark \checkmark$ & & $\checkmark \checkmark$ & $\checkmark \checkmark$ & $\checkmark \checkmark$ & & & \\
\hline & $\checkmark \checkmark$ & $\checkmark \checkmark$ & & & & & & \\
\hline \multirow[t]{2}{*}{$\checkmark \checkmark$} & $\checkmark \checkmark$ & $\checkmark$ & $\checkmark \checkmark$ & $\checkmark \checkmark$ & $\checkmark \checkmark$ & $\checkmark \checkmark$ & $\checkmark \checkmark$ & $\checkmark \checkmark$ \\
\hline & & & $x$ & $x$ & $x$ & $x$ & $\checkmark \checkmark$ & $x$ \\
\hline$\checkmark \checkmark$ & $\checkmark \checkmark$ & $\checkmark \checkmark$ & & $\checkmark \checkmark$ & $\checkmark \checkmark$ & & $\checkmark \checkmark$ & $\checkmark \checkmark$ \\
\hline \multirow[t]{2}{*}{$\checkmark \checkmark$} & & $\checkmark \checkmark$ & $\checkmark \checkmark$ & $\checkmark \checkmark$ & & & & \\
\hline & $\checkmark \checkmark$ & & $\checkmark \checkmark$ & $\checkmark \checkmark$ & $\checkmark \checkmark$ & $\checkmark$ & & $\checkmark \checkmark$ \\
\hline \multirow[t]{4}{*}{$\checkmark \checkmark$} & $\checkmark \checkmark$ & & $\checkmark \checkmark$ & $\checkmark$ & $\checkmark \checkmark$ & $\checkmark$ & $?$ & $\checkmark$ \\
\hline & $\checkmark$ & & $?$ & $\checkmark$ & $\checkmark$ & $\checkmark$ & & $\checkmark$ \\
\hline & & & & $\checkmark$ & $\checkmark \checkmark$ & & & $\checkmark \checkmark$ \\
\hline & & & $?$ & $\checkmark$ & $\checkmark$ & & $?$ & $\checkmark$ \\
\hline \multirow[t]{6}{*}{$\checkmark \checkmark$} & & & $?$ & & & & & \\
\hline & $\checkmark$ & $x$ & $\square$ & $?$ & $x$ & & $?$ & $x$ \\
\hline & & $x$ & $x$ & $?$ & $x$ & & $?$ & $x$ \\
\hline & $\checkmark \checkmark$ & & $\checkmark \checkmark$ & $\checkmark \checkmark$ & $\checkmark$ & & & $\checkmark$ \\
\hline & $\checkmark$ & $\checkmark \checkmark$ & $?$ & $?$ & $x$ & $\checkmark$ & & $x$ \\
\hline & & $x$ & $x$ & $?$ & $x$ & & $?$ & $x$ \\
\hline \multirow[t]{4}{*}{$x$} & & & $x$ & $?$ & $x$ & & & \\
\hline & & & & $?$ & $x$ & & & $x$ \\
\hline & $\checkmark \checkmark$ & & $\checkmark \checkmark$ & $\checkmark$ & & & & $\checkmark$ \\
\hline & $\checkmark \checkmark$ & & $\checkmark \checkmark$ & $\checkmark$ & $\checkmark \checkmark$ & & & $\checkmark \checkmark$ \\
\hline$x$ & & & $x$ & & & & & \\
\hline \multirow[t]{12}{*}{$\checkmark \checkmark$} & & $\checkmark \checkmark$ & $\checkmark \checkmark$ & $\checkmark \checkmark$ & & & & \\
\hline & & & $\checkmark \checkmark$ & $x$ & $x$ & & & \\
\hline & $\checkmark$ & $x$ & $\checkmark \checkmark$ & $\checkmark \checkmark$ & $\checkmark$ & & & \\
\hline & $\checkmark$ & & & & & & & \\
\hline & $\checkmark$ & $x$ & $\checkmark$ & $x$ & $?$ & & & $x$ \\
\hline & & $\square$ & $\checkmark$ & $\checkmark$ & & & & \\
\hline & & $x$ & & & & & & $?$ \\
\hline & $\checkmark$ & $x$ & $\checkmark$ & $\checkmark$ & & & $?$ & $\checkmark$ \\
\hline & & & & & & & $?$ & $\checkmark$ \\
\hline & $x$ & $x$ & & $?$ & $x$ & & $?$ & \\
\hline & & $\checkmark$ & $\checkmark$ & & & $\checkmark \checkmark$ & & \\
\hline & & $x$ & & & $x$ & & $?$ & \\
\hline
\end{tabular}

Page $17 / 20$ 


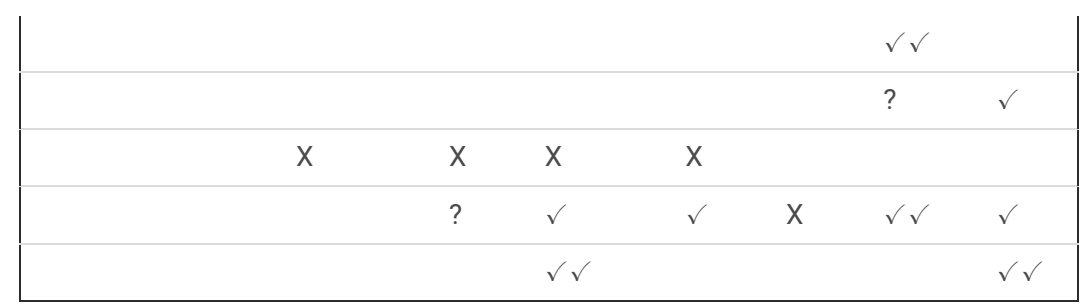

$\checkmark \checkmark$ recommended to do; $\checkmark$ could be considered to do; $X$ do not recommend to do; 『uncertain/unclear.

\section{Figures}
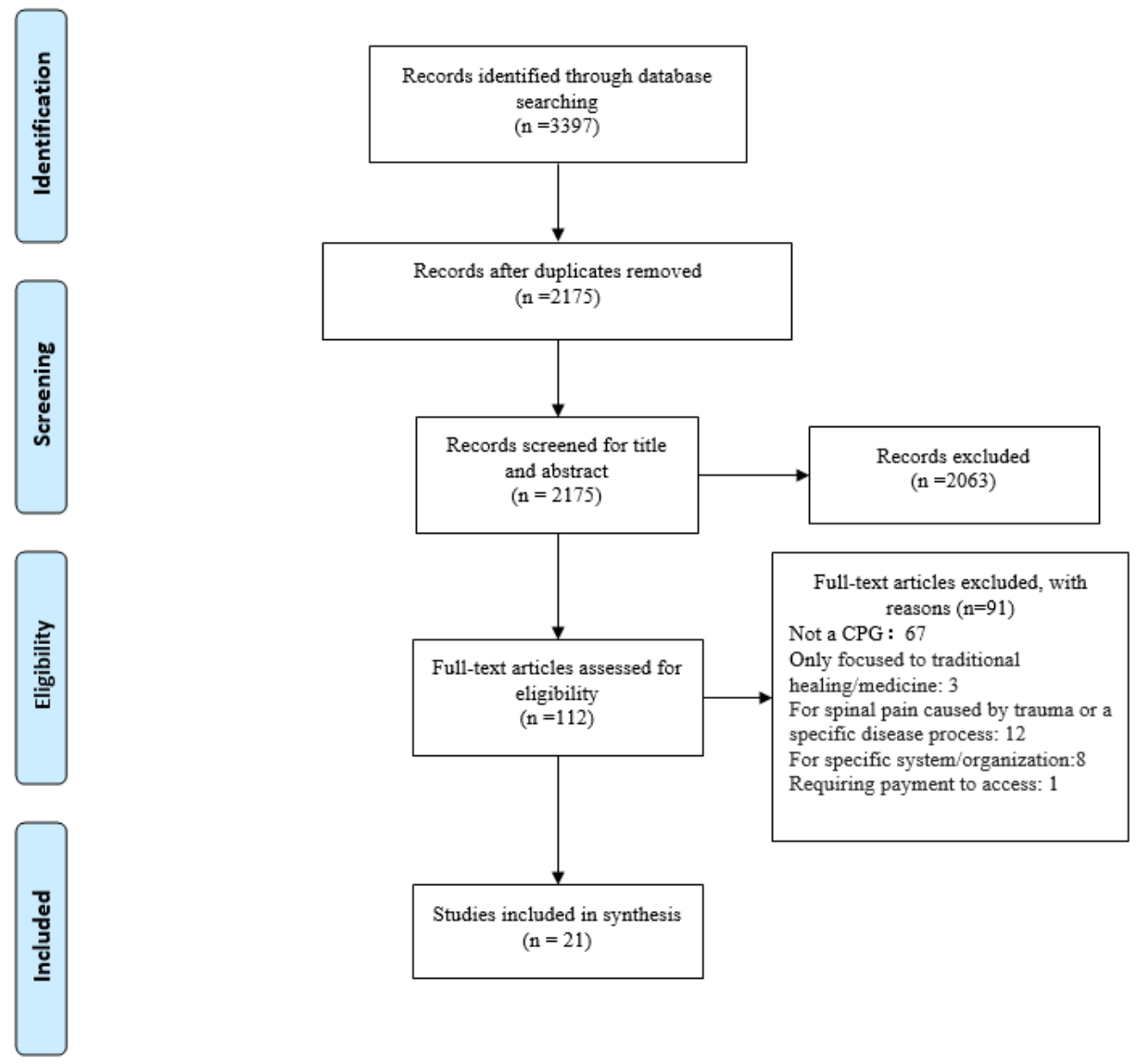

Figure 1

Flow diagram of study identification, screening, eligibility assessment, and inclusion.

A

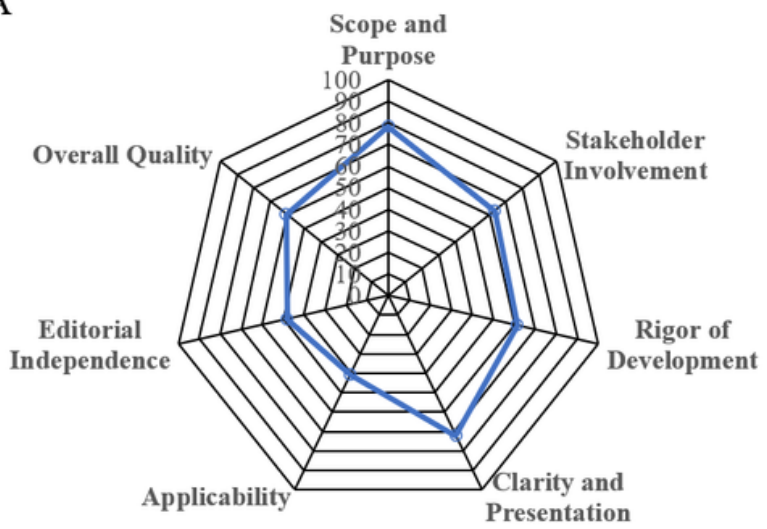

B

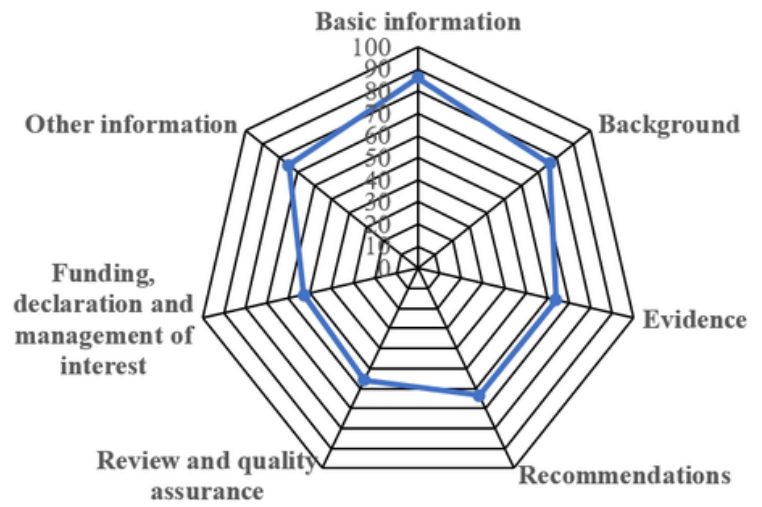


(A) The mean score of each domain according to the AGREE II checklist. (B) The adherence rate of each domain according to the RIGHT checklist. AGREE II: The Appraisal of Guidelines Research and Evaluation; RIGHT: Reporting Items for Practice Guidelines in Healthcare.
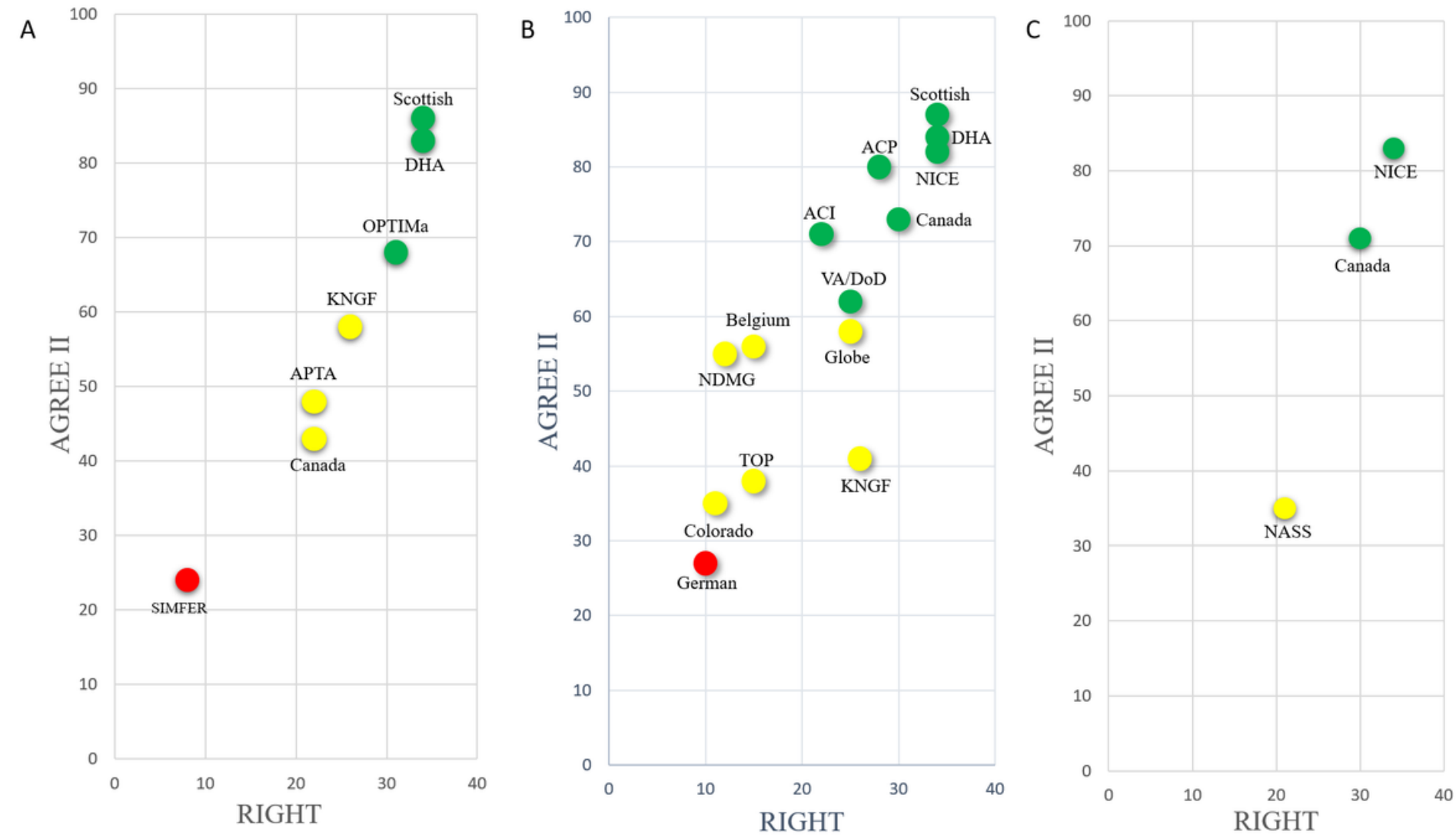

\section{Figure 3}

Grading and analysis of reporting and methodological quality of neck pain CPGs (A), low back pain CPGs (B) and sciatica (C). Different colors represent different CPG quality, with green for high-quality CPGs, yellow for middle-level CPGs, and red for low-level CPGs. KNGF: The Royal Dutch Society for Physical Therapy; APTA: Orthopaedic Section of the American Physical Therapy Association; DHA: Danish Health Authority; OPTIMa: Ontario Protocol for Traffic Injury Management Collaboration; SIGN: Scottish Intercollegiate Guidelines Network; SIMFER: The Italian Society of Physical and Rehabilitation Medicine; ACP: American College of Physicians; ACl: The Agency for Clinical Innovation; NDMG: German Disease Management Guideline; KNGF: Koninklijk Nederlands Genootschap voor Fysiotherapie; TOP: Toward Optimized Practice; VA/DoD: U.S. Department of Veterans Affairs (VA) and U.S. Department of Defense (DoD); NICE: National Institute for Health and Care Excellence; NASS: North American Spine Society. 
A

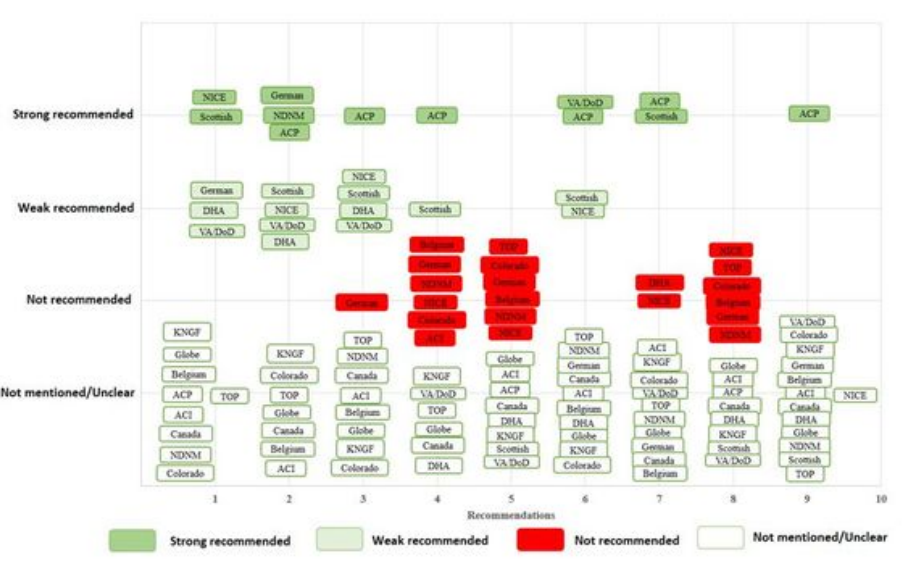

B

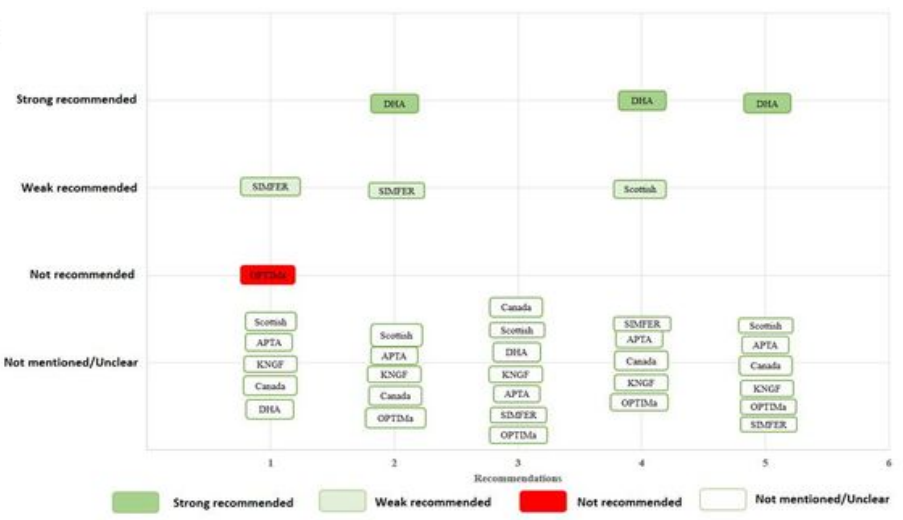

D

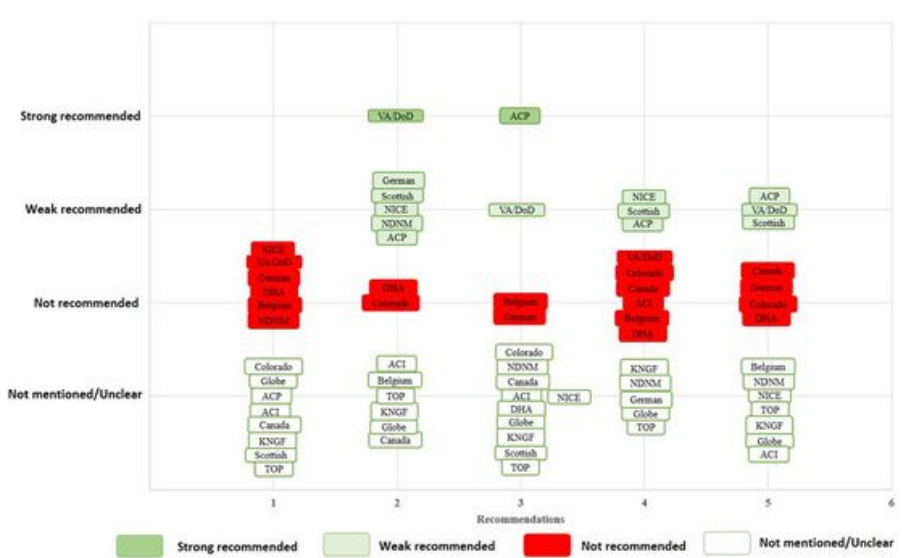

Figure 4

Evidence map of nonpharmacotherapy and pharmacotherapy recommendation of CPGs for neck pain (A, B) and low back pain (C, D), respectively. (A): 1. Education; 2. Exercise; 3. Manual therapy 4. Electrotherapy; 5. Traction; 6. Psychological therapy; 7. Acupuncture; 8. Cervical collar/other medical aids; (B): 1. Paracetamol; 2. NSAIDs; 3. Muscle relaxants; 4. Opioids; 5. Tramadol; (C): 1. Education; 2. Exercise; 3. Manual therapy 4. Electrotherapy; 5 . Traction; 6. Psychological therapy; 7. Acupuncture; 8. Ultrasound; 9. Heat/cold therapy; (D): 1. Paracetamol; 2. NSAIDs; 3. Muscle relaxants; 4. Opioids; 5. Antidepressants. KNGF: The Royal Dutch Society for Physical Therapy; APTA: Orthopaedic Section of the American Physical Therapy Association; DHA: Danish Health Authority; OPTIMa: Ontario Protocol for Traffic Injury Management Collaboration; SIGN: Scottish Intercollegiate Guidelines Network; SIMFER: The Italian Society of Physical and Rehabilitation Medicine; ACP: American College of Physicians; ACl: The Agency for Clinical Innovation; NDMG: German Disease Management Guideline; KNGF: Koninklijk Nederlands Genootschap voor Fysiotherapie; TOP: Toward Optimized Practice; VA/DoD: U.S. Department of Veterans Affairs (VA) and U.S. Department of Defense (DoD); NICE: National Institute for Health and Care Excellence; NASS: North American Spine Society.

\section{Supplementary Files}

This is a list of supplementary files associated with this preprint. Click to download.

- Tables1.docx

- Tables2.docx

- SupplementaryFile1.docx 